\title{
Formation Mechanisms of Alloying Element Nitrides in Recrystallized and Deformed Ferritic Fe-Cr-Al Alloy
}

\author{
MARYAM AKHLAGHI, SAI RAMUDU MEKA, ERIC A. JÄGLE, SILKE J.B. KURZ, \\ EWALD BISCHOFF, and ERIC J. MITTEMEIJER
}

The effect of the initial microstructure (recrystallized or cold-rolled) on the nitride precipitation process upon gaseous nitriding of ternary Fe-4.3 at. pct $\mathrm{Cr}-8.1$ at. pct $\mathrm{Al}$ alloy was investigated at $723 \mathrm{~K}\left(450{ }^{\circ} \mathrm{C}\right)$ employing X-ray diffraction (XRD) analyses, transmission electron microscopy (TEM), atom probe tomography (APT), and electron probe microanalysis (EPMA). In recrystallized Fe-Cr-Al specimens, one type of nitride develops: ternary, cubic, NaCl-type mixed $\mathrm{Cr}_{1-x} \mathrm{Al}_{x} \mathrm{~N}$. In cold-rolled $\mathrm{Fe}-\mathrm{Cr}$-Al specimens, precipitation of two types of nitrides occurs: ternary, cubic, NaCl-type mixed $\mathrm{Cr}_{1-x} \mathrm{Al}_{x} \mathrm{~N}$ and binary, cubic, NaCl-type AlN. By theoretical analysis, it was shown that for the recrystallized specimens an energy barrier for the nucleation of mixed $\mathrm{Cr}_{1-x} \mathrm{Al}_{x} \mathrm{~N}$ exists, whereas in the cold-rolled specimens no such energy barriers for the development of mixed $\mathrm{Cr}_{1-x} \mathrm{Al}_{x} \mathrm{~N}$ and of binary, cubic AlN occur. The additional development of the cubic AlN in the cold-rolled microstructure could be ascribed to the preferred heterogeneous nucleation of cubic AIN on dislocations. The nitrogen concentration-depth profile of the cold-rolled specimen shows a stepped nature upon prolonged nitriding as a consequence of instantaneous nucleation of nitride upon arrival of nitrogen and nitride growth rate-limited by nitrogen transport through the thickening nitrided zone.

DOI: $10.1007 / \mathrm{s} 11661-016-3621-5$

(C) The Author(s) 2016. This article is published with open access at Springerlink.com

\section{INTRODUCTION}

GASEOUS nitriding is one of the most widely employed thermochemical surface treatments to improve the mechanical (wear and fatigue) and chemical (corrosion) properties of ferritic steel components. ${ }^{[1]}$ Gaseous nitriding is carried out in an $\mathrm{NH}_{3} / \mathrm{H}_{2}$ gas mixture. The atomic nitrogen from dissociating $\mathrm{NH}_{3}$ at the surface of the component gets incorporated into the surface of the specimen. ${ }^{[2-6]}$ The inwardly diffusing nitrogen reacts with alloying elements dissolved in the matrix having affinity

MARYAM AKHLAGHI, formerly Ph.D. Student with the Max Planck Institute for Intelligent Systems (formerly Max Planck Institute for Metals Research), Heisenbergstraße 3, 70569 Stuttgart, Germany, is now Research Scientist with the Institute of Iron and Steel Technology, Technische Universität Bergakademie Freiberg, 09599 Freiberg, Germany. Contact e-mail: mry.akhlaghi@gmail.com, m.akhlaghi@is.mpg.de SAI RAMUDU MEKA, formerly Research Scientist with the Max Planck Institute for Intelligent Systems, is now Assistant Professor with the Metallurgical and Materials Engineering Department, Indian Institute of Technology Roorkee, Roorkee, India. ERIC A. JÄGLE, Group Leader, is with the Max-Planck-Institut für Eisenforschung GmbH, Max-Planck-Str. 1, 40237 Düsseldorf, Germany. SILKE J.B. KURZ, formerly Research Scientist with the Max Planck Institute for Intelligent Systems, is now Analysis Engineer with Robert Bosch GmbH, Dieselstraße 6, 72770 Reutlingen, Germany. EWALD BISCHOFF, Research Scientist, is with the Max Planck Institute for Intelligent Systems. ERIC J. MITTEMEIJER, Director, is with the Max Planck Institute for Intelligent Systems and also Professor with the Institute for Materials Science, University of Stuttgart, Heisenbergstraße 3, 70569 Stuttgart, Germany

Manuscript submitted November 24, 2015.

Article published online July 8, 2016 for nitrogen (as $\mathrm{Cr}$ and $\mathrm{Al}$ ) and forms alloying element nitrides. ${ }^{[7]}$ Understanding the collective interaction of multiple alloying elements with nitrogen is a prerequisite for understanding the nitriding behavior of steels.

It is generally recognized that the characteristics of the microstructure can decisively influence the mechanism of a precipitation process. ${ }^{[8]}$ Thus, investigations on the recrystallized and cold-rolled specimens of binary $\mathrm{Fe}-\mathrm{Al}^{[9,10]}$ and $\mathrm{Fe}-\mathrm{Mo}^{[11]}$ alloys have revealed that the crystal lattice defects in cold-rolled specimens can lead to different nitride modifications and drastically influence the precipitation kinetics.

Fundamental research on nitride precipitation processes until now has been largely devoted to recrystallized, i.e., more or less deformation-less, specimens and has focused on binary $\mathrm{Fe}-M e_{1}$ iron-based alloys: $\mathrm{Fe}-\mathrm{Cr},{ }^{[12-16]} \mathrm{Fe}-\mathrm{Al},{ }^{[10,17]} \mathrm{Fe}-\mathrm{V},{ }^{[18,19]} \mathrm{Fe}-\mathrm{Ti},{ }^{[20-22]}$ and

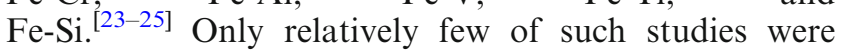
devoted to recrystallized, ternary, iron-based $\mathrm{Fe}-\mathrm{Me}_{1^{-}}$ $M e_{2}$ alloys, where two types of dissolved elements, $M e_{1}$ and $\mathrm{Me}_{2}$, compete with each other in reacting with nitrogen. ${ }^{[26-37]}$ In a number of cases, the surprising development of metastable ternary mixed $\left(M e_{1}, M e_{2}\right) \mathrm{N}$ nitrides was observed: cubic NaCl-type $\mathrm{Cr}_{1-x} \mathrm{Al}_{x} \mathrm{~N}$, $\mathrm{Cr}_{1-x} \mathrm{Ti}_{x} \mathrm{~N}$, and $\mathrm{Cr}_{1-x} \mathrm{Mo}_{x} \mathrm{~N}$ in Fe-Cr-Al, Fe-Cr-Ti, and $\mathrm{Fe}-\mathrm{Cr}-\mathrm{Mo}$ alloys, respectively. ${ }^{[28,31,38]}$ It may be expected that the precipitation process of such metastable mixed nitrides can be highly sensitive to the nature of the initial microstructure.

Against the above background, the present project aims to reveal the role of microstructural defects on the 
Table I. Chemical Analysis of Fe-Cr-Al Alloy of This Work

\begin{tabular}{|c|c|c|c|c|c|c|c|}
\hline \multirow[b]{2}{*}{ Element } & \multicolumn{2}{|c|}{$\mathrm{Cr}$} & \multicolumn{2}{|c|}{$\mathrm{Al}$} & \multirow{2}{*}{$\begin{array}{c}\text { O } \\
\text { Weight Pct }\end{array}$} & \multirow{2}{*}{$\frac{\mathrm{N}}{\text { Weight Pct }}$} & \multirow{2}{*}{$\begin{array}{c}\text { C } \\
\text { Weight Pct }\end{array}$} \\
\hline & Weight Pct & Atomic Pct & Weight Pct & Atomic Pct & & & \\
\hline $\mathrm{Fe}-\mathrm{Cr}-\mathrm{Al}$ & $4.17 \pm 0.05$ & $4.28 \pm 0.05$ & $4.12 \pm 0.05$ & $8.14 \pm 0.10$ & $0.006 \pm 0.002$ & $<0.001$ & 0.002 \\
\hline
\end{tabular}

Metal contents were determined by inductively coupled plasma-optical emission spectroscopy; the contents of light element impurities were determined by carrier gas hot extraction $(\mathrm{O}, \mathrm{N})$ and a combustion method $(\mathrm{C})$.

development of nitride precipitates in iron-based ternary $\mathrm{Fe}-\mathrm{Cr}-\mathrm{Al}$ alloys, thereby exposing differences in the interactions of $\mathrm{Cr}$ and $\mathrm{Al}$ with $\mathrm{N}$. To this end, nitriding experiments were performed on both the cold-rolled and recrystallized specimens of $\mathrm{Fe}-\mathrm{Cr}-\mathrm{Al}$ alloys. Low-temperature nitriding at $723 \mathrm{~K}\left(450{ }^{\circ} \mathrm{C}\right)$ was carried out in order to minimize the possible occurrence of recrystallization of the cold-rolled specimens during nitriding. The experimental observations were discussed regarding the thermodynamics of the occurring precipitation processes.

\section{EXPERIMENTAL}

\section{A. Specimen Preparation and Nitriding}

Fe-4.3 at. pet $\mathrm{Cr}-8.1$ at. pet Al ternary alloy was prepared by melting appropriate amounts of pure $\mathrm{Fe}$ (99.98 wt pct), pure $\mathrm{Cr}$ (99.999 wt pct), and pure $\mathrm{Al}$ (99.999 wt pct) in an $\mathrm{Al}_{2} \mathrm{O}_{3}$ crucible under a protective argon gas (99.999 vol. pct) atmosphere. Subsequently, the melts were cast in a cylindrical (diameter of $10 \mathrm{~mm}$ and a length of $100 \mathrm{~mm}$ ) copper mold. The results of chemical analysis of the produced cast alloy are presented in Table I. The cast rods were cold-rolled to sheets of $1 \mathrm{~mm}$ thickness (degree of deformation is 90 pct). From these sheets, specimens were cut with lateral dimensions of $1 \times 1.5 \mathrm{~cm}^{2}$. After grinding and polishing (finishing with $1 \mu \mathrm{m}$ diamond suspension) of the specimen surface, some of the specimens were directly nitrided in their deformed state. The other specimens were, before nitriding, annealed: $\mathrm{Fe}-\mathrm{Cr}-\mathrm{Al}$ specimens were annealed at $1123 \mathrm{~K}\left(850{ }^{\circ} \mathrm{C}\right)$ for 2 hours under $\mathrm{H}_{2}$ atmosphere to obtain a recrystallized grain structure with an average grain size of 40 to $50 \mu \mathrm{m}$.

The specimens to be nitrided were suspended with a quartz fiber in a vertical quartz tube furnace where nitriding occurred in an ammonia/hydrogen gas flux (purity: $\mathrm{H}_{2}: 99.999$ vol. pct; $\mathrm{NH}_{3}:>99.998$ vol. pet). The fluxes of both gases $\left(45 \mathrm{~mL} \mathrm{~min}{ }^{-1} \mathrm{NH}_{3}\right.$ and $455 \mathrm{~mL} \mathrm{~min}^{-1} \mathrm{H}_{2}$ ) were adjusted with mass flow controllers to achieve a nitriding potential of $r_{\mathrm{N}}=0.104$ $\mathrm{atm}^{-1 / 2}{ }^{[5]}$ Nitriding experiments were performed for the $\mathrm{Fe}-\mathrm{Cr}-\mathrm{Al}$ alloy at $723 \mathrm{~K}\left(450{ }^{\circ} \mathrm{C}\right)$ for 72 and 144 hours. The employed nitriding potential is below the critical nitriding potential necessary for $\left(\gamma^{\prime}\right)$ iron-nitride formation upon nitriding pure iron at $723 \mathrm{~K}\left(450{ }^{\circ} \mathrm{C}\right) \cdot{ }^{[39,40]}$

\section{B. Microstructural Characterization}

\section{Metallography}

For metallographic investigation of the nitrided zone, a piece of the nitrided $\mathrm{Fe}-\mathrm{Cr}-\mathrm{Al}$ specimen was cut from the specimen, normal to the specimen surface, and embedded in Struers PolyFast. The cross sections were then ground and polished (final polishing using $1 \mu \mathrm{m}$ diamond suspension). The specimens were etched with 4 pct Nital for about 15 seconds at room temperature. For light microscopy, a Zeiss Axiophot microscope equipped with a digital camera (Olympus ColorView IIIu) was used.

Hardness-depth profiles across the nitrided zone were measured using a Vickers Microhardness tester (Leica VMHT Mot) applying a load of $10 \mathrm{~g}$ and a dwell time of 10 seconds. The depicted hardness value per depth is an average of five measured values.

\section{Electron probe microanalysis (EPMA)}

To determine the elemental concentrations ( $\mathrm{Al}, \mathrm{Cr}, \mathrm{N}$, and $\mathrm{Fe}$ ) of the nitrided zone, electron probe microanalysis (EPMA) was performed on the cross section of nitrided specimens. For these measurements, a Cameca SX100 microprobe (acceleration voltage $U=10 \mathrm{kV}$, current $I=100 \mathrm{nA}$, spot size about $1 \mu \mathrm{m}$ ) was used. To obtain the element contents at each measurement point, the intensities of the characteristic X-ray emission peaks were measured and divided by the corresponding intensities obtained from standard samples of pure Fe, $\mathrm{Cr}, \mathrm{Al}$, and $\gamma^{\prime}-\mathrm{Fe}_{4} \mathrm{~N}$ (for $\mathrm{N}$ ). Elemental concentrations were calculated from the intensity ratios applying the $\Phi(\rho z)$ approach. ${ }^{[11]}$

\section{X-ray diffraction (XRD) analyses}

For phase analysis, X-ray diffractograms were recorded [in a diffraction angle $(2 \theta)$ range of 30 to 105 deg, applying a step size of $0.02 \mathrm{deg}$ in $2 \theta$ with a counting time of 300 seconds per step] from the surface of the Fe-Cr-Al specimens before and after nitriding using a PANalytical X'Pert diffractometer with BraggBrentano configuration, applying $\mathrm{Co}-\mathrm{K}_{\alpha}$ radiation and a graphite monochromator in the diffracted beam. During the measurements, the specimens were rotated around their surface normal to improve the crystallite statistics. In order to identify the different phases from the peaks 
in the diffraction pattern, the ICDD database was used. ${ }^{[42]}$

Depth-resolved diffraction analysis of the stress and the "strain-free" lattice parameter* was performed on

*The notation "strain-free" is put between quotation marks to indicate the possibility of an additionally acting hydrostatic strain (cf. discussion is Section III-B).

the cross section of the cold-rolled $\mathrm{Fe}-\mathrm{Cr}-\mathrm{Al}$ specimen nitrided for 144 hours in transmission mode at the High Energy Materials Science (HEMS) beamline P07 at PETRA III ${ }^{[43]}$ utilizing a new method described in Reference 44. In the current research, the stress and the "strain-free" lattice parameter were determined as a function of depth in the nitrided zone employing the ferrite 211 reflection. It can be assumed that a planar, rotationally symmetric stress state parallel to the original specimen surface prevails. ${ }^{[4,45]}$ Then, the measured X-ray elastic strain at different tilt angles $\psi$ (the angle between the diffraction vector and the specimen surface normal) is related to the macroscopic, mechanical stress by the diffraction elastic constants for each $h k l$ reflection. The "strain-free" lattice parameter was obtained by interpolation at the "strain-free" direction for 211 lattice planes (see Reference 46).

In the course of the evaluation of the measured data of a previous study, ${ }^{[4]}$ it was found that confining the analysis to only two $\psi$ angles, namely $\psi=0 \mathrm{deg}$ and $\psi=90 \mathrm{deg}$, led to the same results for residual stress and "strain-free" lattice parameter as a function of depth as obtained from the data analysis based on more $\psi$ angles. This observation enhances the fast and convenient character of the evaluation of the experimental data in the here-proposed dynamical cross-sectional transmission microdiffraction method.

Experimental errors in the values of the stress and the "strain-free" lattice parameter were assessed from the uncertainty in the determination of the peak position upon fitting. The effect of relaxation of residual stress during cutting of specimen, to prepare the cross section investigated, can be neglected as shown in Reference 44. The values assigned to the measured "strain-free" lattice parameters are based on calibration of the "strain-free" lattice parameter of the unnitrided specimen core of the ternary Fe-4.3 at. pct $\mathrm{Cr}-8.1$ at. pet $\mathrm{Al}$ alloy as follows.

The lattice parameter of the unnitrided Fe-4.3 at. pct $\mathrm{Cr}-8.1$ at. pet $\mathrm{Al}$ alloy was calculated from the following data: (i) the lattice parameter of pure iron taken as $2.8664 \AA{ }^{[42]}$ (ii) the lattice parameter increase of iron per at. pct of dissolved $\mathrm{Cr}$ which equals $+0.0005 \AA{ }^{[47]}$ and (iii) the lattice parameter increase of iron per at. pct of dissolved $\mathrm{Al}$ which is given by $+0.0015 \AA .{ }^{[47]}$ The adopted lattice parameter of Fe-4.3 at. pet $\mathrm{Cr}-8.1$ at. pet Al alloy then is assessed at $[2.8664+(4.3 \times 0.0004)+$ $(8.1 \times 0.0015)] \AA=2.8803 \AA$.

\section{Transmission electron microscopy (TEM)}

Electron transparent foils for TEM investigations were prepared from material taken at 20 and $60 \mu \mathrm{m}$ depths from the surface of both cold-rolled and recrystallized $\mathrm{Fe}-\mathrm{Cr}-\mathrm{Al}$ specimens nitrided for 144 hours at $723 \mathrm{~K}\left(450{ }^{\circ} \mathrm{C}\right)$. To this end, self-supporting disks (Ø3 $\mathrm{mm}$ ) were stamped with a mechanical punch from sheets produced by removing material mechanically from both surfaces of the nitrided specimens. These disks were ground, dimpled, and, subsequently, Ar-ion milled (voltage: $4 \mathrm{kV}$, current: $5 \mathrm{~mA}$, angle of ion incidence with respect to the surface of the disk: $8 \mathrm{deg}$, milling time: 4.5 hours; liquid nitrogen cooling stage). TEM analysis was performed using a Philips CM 200 transmission electron microscope operating at $200 \mathrm{kV}$. Bright-field (BF) and dark-field (DF) images and the corresponding selected area diffraction patterns (SADPs) were recorded using a CCD camera from Gatan.

\section{Atom probe tomography (APT)}

The composition of individual nitride precipitates in the cold-rolled ternary Fe-Cr-Al specimen was investigated by atom probe tomography (APT). For the APT measurements, a reflectron-equipped LEAP $3000 \times \mathrm{HR}$ (Cameca Instruments, Madison, Wisconsin) was used in laser-pulsing mode. The target temperature of the specimen was maintained at $60 \mathrm{~K}\left(-213{ }^{\circ} \mathrm{C}\right)$, the pulse energy corresponded to $0.4 \mathrm{~nJ}$, the pulse frequency was $250 \mathrm{kHz}$, and the target "evaporation rate," i.e., the average relative number of detector events per applied laser pulse, was 1 pct. In each experiment, about 16 to 27 million ions were collected.

The tips employed for APT were prepared applying focused ion beam (FIB) milling in a SEM/FIB dual-beam microscope (FEI Helios NanoLab 600) equipped with a micromanipulator allowing the standard lift-out procedure. ${ }^{[4]}$ The wedge $\left(20 \times 2 \mu \mathrm{m}^{2}\right)$ was cut out from the surface of a cross-sectional specimen. The long axis of the wedge was oriented parallel to the nitrided surface and the specimens were thus taken from a defined depth below the nitride surface that was measured in the SEM. Final annular milling of the APT tips was carried out with a low acceleration voltage ( 5 $\mathrm{kV}$ ) and a low beam current (40 pA) to minimize Ga contamination of the tip. The final tip radius was below $20 \mathrm{~nm}$. Data analysis was performed using the software package IVAS (version 3.6.8, by Cameca Instruments).

The analysis of the APT measurements is rendered difficult because both ${ }^{27} \mathrm{Al}^{+}$and ${ }^{54} \mathrm{Fe}^{2+}$ (and a minor amount of ${ }^{54} \mathrm{Cr}^{2+}$ ) show a peak at $27 \mathrm{Da}$ in the mass-to-charge ratio spectrum, hence making the distinction between iron and aluminum (and chromium) atoms impossible for atoms detected at this mass-tocharge ratio. However, the concentrations of $\mathrm{Al}, \mathrm{Fe}$, and $\mathrm{Cr}$ can be corrected for this peak overlap, using the nonoverlapped peak at $28.5 \mathrm{Da}$ (corresponding to ${ }^{57} \mathrm{Fe}^{2+}$ ions) and the nonoverlapped peaks at 26 and 26.5 Da (corresponding to ${ }^{52} \mathrm{Cr}^{2+}$ and ${ }^{53} \mathrm{Cr}^{2+}$ ions) and the known natural abundances ${ }^{[49]}$ of the isotopes of $\mathrm{Fe}$ and $\mathrm{Cr}$. Additionally, it is known that $\mathrm{N}_{2}{ }^{+}$ions field evaporate in APT experiments, ${ }^{[50]}$ but because they are detected at $28 \mathrm{Da}$, together with the main peak of the matrix element, iron, $\left({ }^{56} \mathrm{Fe}^{2+}\right)$, their number can only be determined by peak decomposition using the minor peak at 28.5 Da (corresponding to ${ }^{57} \mathrm{Fe}^{2+}$ ions). It may 

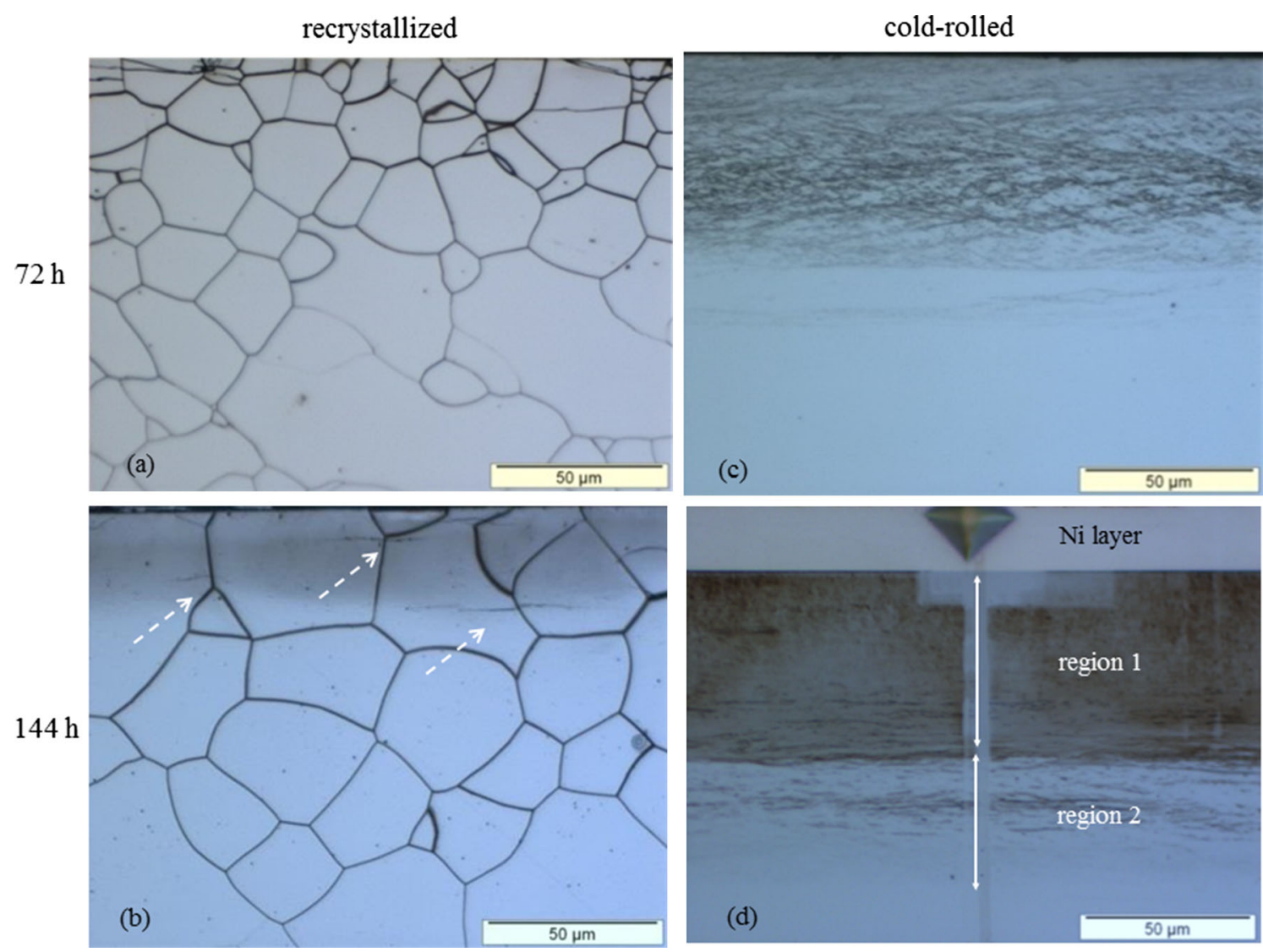

Fig. 1-Light optical micrographs of etched cross sections of Fe-Cr-Al specimens; recrystallized specimens nitrided for $(a) 72 \mathrm{~h}$ and $(b) 144 \mathrm{~h}$ and cold-rolled specimens nitrided for $(c) 72 \mathrm{~h}$ and $(d) 144 \mathrm{~h}$. Dotted white arrows in image (b) depict the microcracks developed near the surface of the prolongedly nitrided recrystallized specimen. The carbon contamination trace of the EPMA scan can be seen in image (d) (at the indication of the depth ranges of region 1 and region 2).

therefore be expected that all nitrogen concentrations determined by peak decomposition in this work contain considerable errors.

\section{RESULTS AND DISCUSSION}

\section{A. Morphology of the Nitrided Zone in Recrystallized and Cold-Rolled $\mathrm{Fe}-\mathrm{Cr}$-Al Alloys}

Light optical micrographs recorded from the cross sections of recrystallized and cold-rolled specimens nitrided for 72 and 144 hours are shown in Figure 1. Evidently, the diffusion zone of the cold-rolled specimens is more strongly etched than that of the recrystallized specimens where only the grain boundaries in the nitrided zone are strongly etched. Upon prolonged nitriding of the cold-rolled specimen, two distinctly and differently etched regions can be distinguished within the nitrided zone: a surface-adjacent, strongly etched zone (marked as region 1 in Figure 1(d)) followed by a less strongly etched region (marked as region 2 in Figure 1(d)), whereas no such distinction in etching response is observed for the recrystallized specimen (see Figure 1(b)). This occurrence of two differently etched zones in the nitrided region of the cold-rolled specimens corresponds with a similar distinction observed in the composition-depth, residual stress-depth, and hardness-depth profiles (see Section III-C).

$\mathrm{X}$-ray diffraction patterns recorded from the surface of nitrided recrystallized and nitrided cold-rolled specimens reveal a nitriding-induced extreme broadening and shift of the ferrite-matrix peaks; no reflections of alloying element nitrides could be detected (see Figures 2(a) and (b)). Such effects have been extensively discussed (for nitrided binary alloys) in Reference 51: The pronounced ferrite-peak broadening is attributed to the microstrains introduced into the ferrite matrix by the development of misfitting (semi-)coherent nitride precipitates. In addition to this peak broadening, a distinct peak shift to lower $2 \theta$ diffraction angles occurs (see $\mathrm{X}$-ray diffraction patterns of the specimens nitrided for 72 hours in Figures 2(a) and (b)). This effect is a direct consequence of the matrix dilatation caused upon elastic accommodation of the precipitates/matrix misfit ${ }^{[52,53]}$ and/or the development of residual compressive macrostress parallel to the surface in the surface-adjacent, nitrided region. ${ }^{[44,45]}$ Upon prolonged nitriding, the relaxation of misfit strains, also in association with the formation of microcracks (see arrows in Figure 1(b)), results in a backshift of the ferrite peaks toward the location expected for unstrained ferrite (see X-ray 
recrystallized

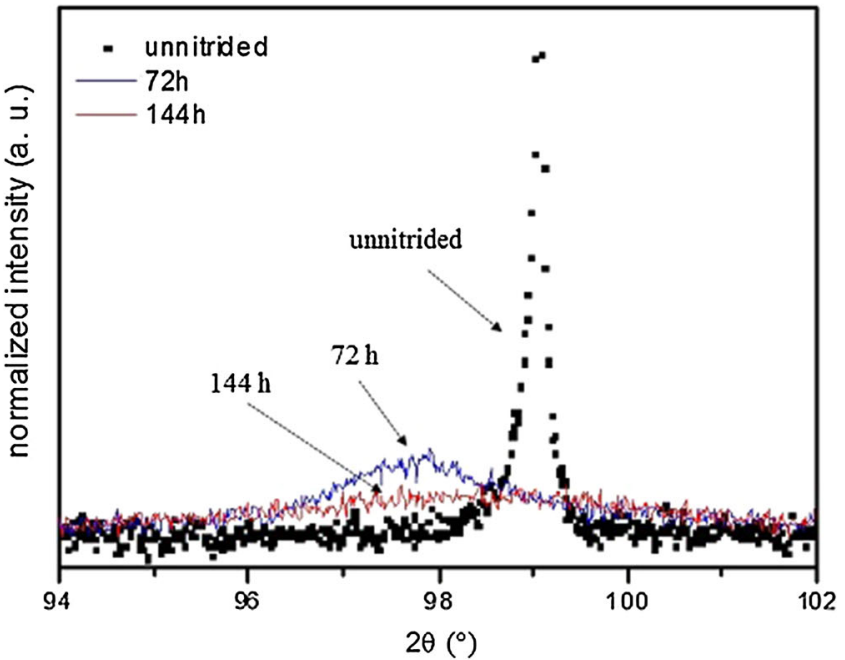

(a)

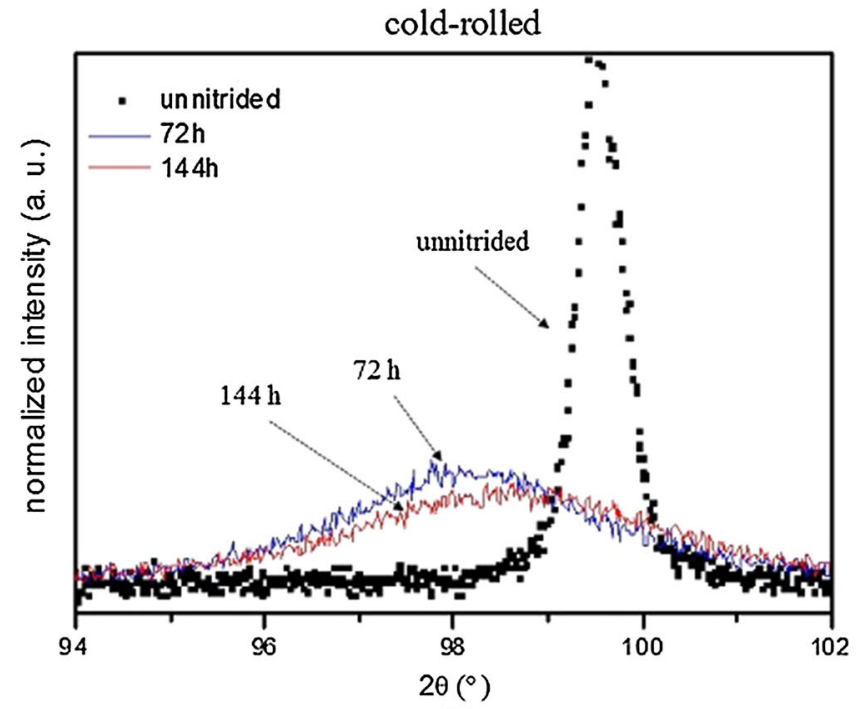

(b)

Fig. 2-X-ray diffractograms (Co- $\mathrm{K}_{\alpha}$ radiation), around the location of the 211 ferrite-matrix reflection, recorded from the surface of (a) the recrystallized $\mathrm{Fe}-\mathrm{Cr}-\mathrm{Al}$ specimen before and after nitriding and $(b)$ the cold-rolled $\mathrm{Fe}-\mathrm{Cr}-\mathrm{Al}$ specimen before and after nitriding.

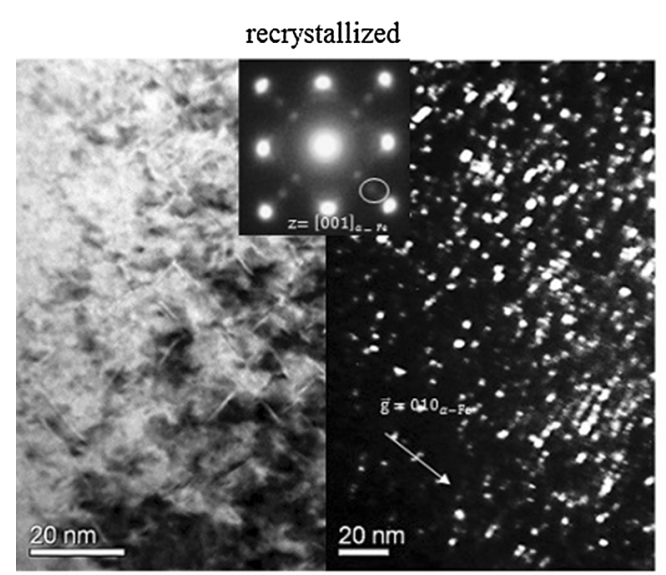

(a)

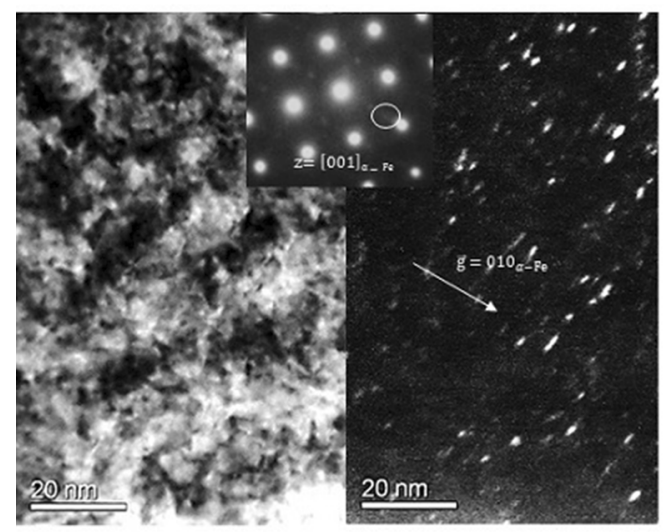

(b)

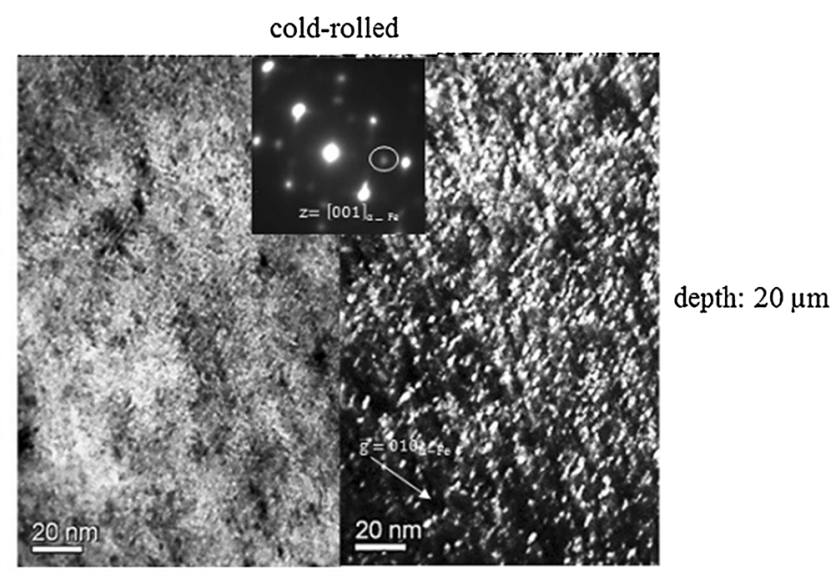

(c)

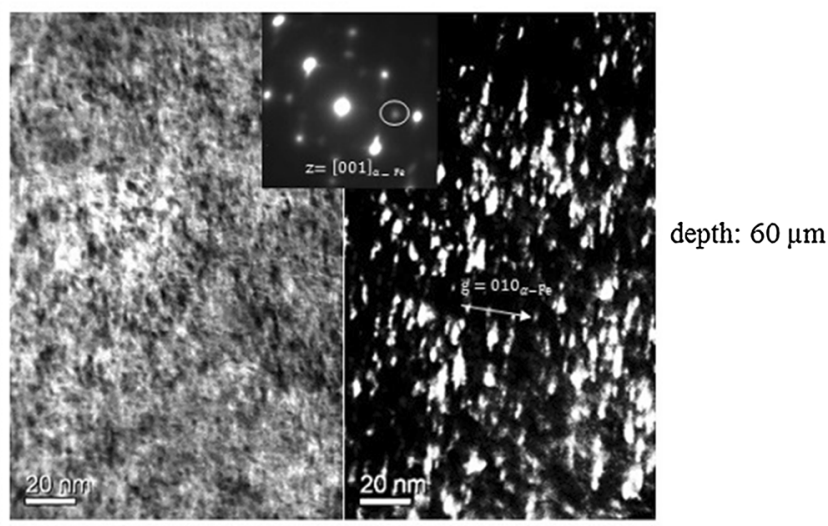

(d)

Fig. 3-TEM bright-field micrographs (left), [001 $]_{\alpha-\mathrm{Fe}}$ zone axis SADP (inset), and dark-field micrographs (right) of a recrystallized Fe-Cr-Al specimen nitrided for $144 \mathrm{~h}$, recorded from the depths of $(a) 20 \mu \mathrm{m}$ and $(b) 60 \mu \mathrm{m}$. TEM bright-field micrographs (left), [001] $\alpha$-Fe zone axis SADP (inlay), and dark-field micrographs (right) of a cold-rolled Fe-Cr-Al specimen nitrided for $144 \mathrm{~h}$, recorded from the depths of $(c) 20 \mu \mathrm{m}$ (region 1 in Fig. 1(d)) and (d) $60 \mu \mathrm{m}$ (region 2 in Fig. 1(d)). The aperture positions for the DF images have been indicated by a white circle in the corresponding SADPs and were chosen on the streak/spot originating from one variant of the cubic nitride precipitates. 
Table II. Average Concentrations for Various Parts of the Specimen (Tip) as Determined by APT (See Fig. 7)

\begin{tabular}{lccrr}
\hline Part of the Dataset & Iso-conc. Surface & N (Pct) & Cr (Pct) & Fe (Pct) \\
\hline Region 1 & & & & \\
$\quad$ Al-nitride & $\mathrm{Al}>50 \%$ & 35.4 & 1.2 & 62.0 \\
$\quad$ Mixed nitride & $\mathrm{Cr}>13 \%$ & 27.1 & 23.5 & 30.4 \\
Region 2 & $\mathrm{Al}>50 \%$ & 44.5 & 0.3 & 19.0 \\
Al-nitride & $\mathrm{Cr}>13 \%$ & 26.6 & 18.9 & 54.0 \\
Mixed nitride & & & 29.0 \\
\hline
\end{tabular}

All concentrations are shown in at. pct. The iso-concentration surfaces on which the calculations are based have been given for each dataset. Note that, e.g., the nitrogen concentration contains contributions from nitrogen atoms evaporated as $\mathrm{N}_{2}{ }^{-}$ions, AlN-ions, etc. For a discussion on the limited accuracy of these composition data, see in particular Section III-B.

diffraction patterns of the specimens nitrided for 144 hours in Figures 2(a) and (b)).

TEM BF and DF images and the corresponding SADPs of foils of nitrided recrystallized and nitrided cold-rolled specimens (taken at the depths of 20 and $60 \mu \mathrm{m}$ below the surface; these selected depths are within the depth ranges of regions 1 and 2 of the cold-rolled specimen as indicated in Figure 1(d)) are shown in Figure 3. Nanosized precipitate platelets have developed along $\{100\}$ habit planes of the ferrite matrix. In the SADPs, in addition to intense diffraction spots of the ferrite matrix, less intense diffraction spots are present which can be indexed according to cubic NaCl-type structured precipitates having a lattice parameter close to $2^{1 / 2}$ times the lattice parameter of ferrite. Further, the locations of the diffraction spots of these precipitates with respect to the ferrite-matrix spots are according to a Baker-Nutting orientation relationship (OR) of the precipitates with the matrix. ${ }^{[54]}$ The lattice parameters of cubic NaCl-type $\mathrm{CrN}(4.14 \AA$ ) and AlN (4.04 $\AA)^{[42]}$ are close to each other and both nitrides are known to maintain a Baker-Nutting OR with the matrix. It is thus expected that the lattice parameter of a ternary, cubic, NaCl-type mixed $\mathrm{Cr}_{1-x} \mathrm{Al}_{x} \mathrm{~N}$ nitride would have a value between $4.04 \AA$ and $4.14 \AA$. Further noticing the apparent absence of hexagonal wurtzitetype AlN in both cold-rolled and recrystallized specimens, it is suggested that the precipitates which developed in nitrided Fe-Cr-Al alloy are either both cubic $\mathrm{NaCl}$-type $\mathrm{CrN}$ and cubic $\mathrm{NaCl}$-type AlN or a ternary, "mixed," cubic, $\mathrm{NaCl}$-type $\mathrm{Cr}_{1-x} \mathrm{Al}_{x} \mathrm{~N}$ nitride. ${ }^{[38,55]}$

According to Figures 3(c) and (d), the size of the nitrides increases and the density of the nitrides decreases with increasing nitriding depth in the coldrolled specimen (see DF images taken at the depths of $20 \mu \mathrm{m}$ and $60 \mu \mathrm{m}$ below the surface of cold-rolled specimen).

\section{B. Composition of Nitride Precipitates}

In order to clarify the composition of precipitates developing in regions 1 and 2 of the cold-rolled $\mathrm{Fe}-\mathrm{Cr}-\mathrm{Al}$ alloy, atom probe tomography analyses (see Section II-B-5) were performed for these two depth regions. Datasets for measurements with material from region 1 and material from region 2 are depicted in
Figures 4(a) and (b), respectively. In these figures, iso-concentration surfaces have been indicated to delineate different nitrides. Inside the cyan surfaces, the aluminum concentration is at least 50 at. pct, while inside the pink surfaces, the chromium concentration is at least 13 at. pct. Evidently, according to the compositions inside these iso-concentration surfaces, as determined by APT and presented in Table II, two types of precipitates can be identified: Al-nitrides (cyan surfaces in Figures 4(a) and (b)) and Cr-Al-mixed nitrides (pink surfaces in Figures 4(a) and (b)); see later for discussion of the inaccuracy of the compositional analysis.

Comparing the $\mathrm{Cr}$ and $\mathrm{Al}$ concentrations obtained for the Cr-Al-mixed nitrides in Table II, it follows that the $\mathrm{Al} / \mathrm{Cr}$ ratio of the mixed nitride is smaller for region 1 than for region 2 (i.e., $\mathrm{Al} / \mathrm{Cr}$ is 0.8 for (the "oldest" nitrided) region 1 and 1.3 for (the "newest" nitrided) region 2). This can be understood as a consequence of the depletion of $\mathrm{Al}$ from the $\mathrm{Cr}$-Al-mixed nitrides, as initially precipitated (i.e., in the "newest" nitrided region 2 ), in favor of the development of separate cubic Al-nitride, occurring upon prolonged nitriding (=aging), as can take place (in the fully and "oldest" nitrided region 1); see discussion in Section IV.

According to Figure 4, the nitride precipitates developing in region 1 are considerably smaller in size and of higher density than those in region 2. This is in agreement with the corresponding TEM DF images of regions 1 and 2 as shown in Figures 3(c) and (d), respectively. This reflects the enhanced nitride nucleation kinetics as a result of higher $\mathrm{N}$ supersaturation and thus larger driving force for the nitride precipitation in the surface-adjacent region, ${ }^{[56]}$ as confirmed by recent computer simulations. ${ }^{[57]}$

The morphology of the nitrides is rather irregular (see Figures 4(a) and (b)). Some of the nitrides (both Cr-Al-mixed and Al-nitrides) in region 1 (Figure 4(a)) are very small $(\leq 1 \mathrm{~nm})$, while the others are elongated and up to $10 \mathrm{~nm}$ long. In region 2 (Figure 4(b)), the two different nitrides exhibit quite different morphologies: the mixed nitride particles (pink surfaces) occur as fine nitrides sometimes arranged in rows leading to needle-type configurations; the Al-nitride particles (cyan surfaces) are much coarser, tending to equiaxed shape. 

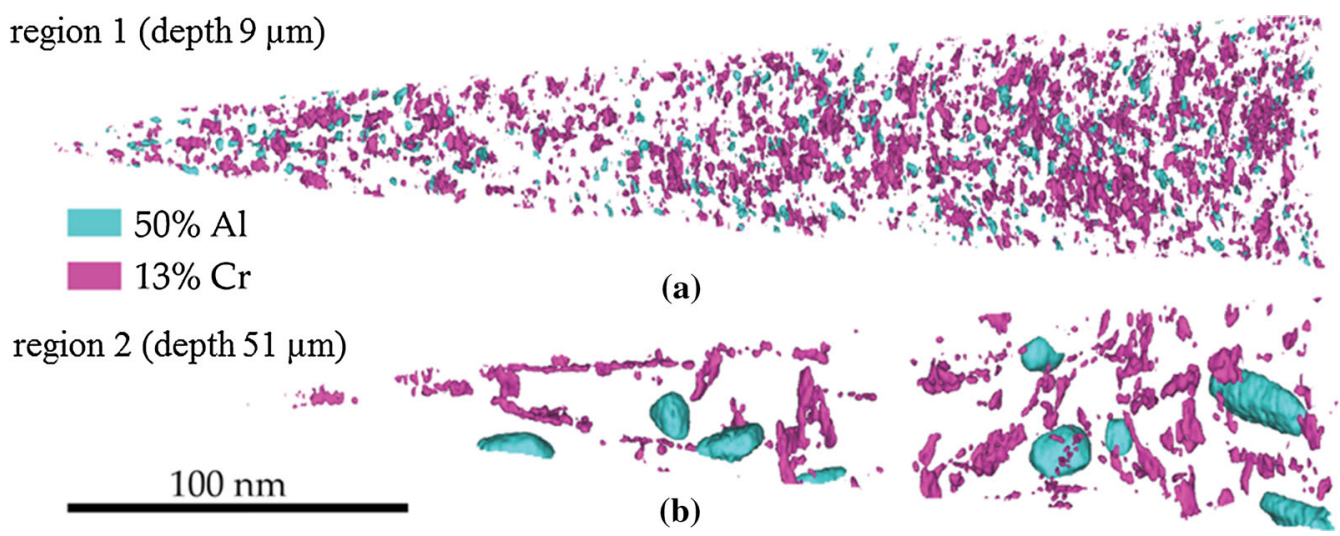

Fig. 4-Atom probe tomography (APT) datasets showing the distribution and morphologies of nitrides for a depth of $(a)$ about $9 \mu \mathrm{m}$ (region 1$)$ and $(b)$ about $51 \mu \mathrm{m}$ (region 2) below the surface of the nitrided cold-rolled $\mathrm{Fe}-\mathrm{Cr}$-Al specimen. The nitrides have been visualized by iso-concentration surfaces. The cyan $50 \mathrm{pct} \mathrm{Al}$ iso-concentration surfaces delineate the Al-nitrides and the pink iso-concentration surfaces at 13 pet $\mathrm{Cr}$ delineate the mixed nitride (for the composition of the nitrides, see Table II).

The problematic determination of the composition of the nitrides by APT can be discussed as follows:

(i) Peak overlaps (see also Section II-B-5)

Sections of the mass spectra of the (i) entire specimen, (ii) inside the Al-nitrides (cyan surfaces), and (iii) inside the mixed nitrides (pink surfaces) are shown for regions 1 and 2 in Figures 5(a) and (b), respectively. The natural abundances of various isotopes of $\mathrm{Fe}$ and $\mathrm{N}$ are also shown as colored lines. In the mass-to-charge spectrum of the entire measurement (representative of the overall composition of the specimen) from regions 1 and 2 (top rows in Figures 5(a) and (b)), peak overlaps occurs, e.g., at $28 \mathrm{Da}\left({ }^{56} \mathrm{Fe}^{2+}\right.$ peak and $\mathrm{N}_{2}{ }^{+}$peak $)$and at $29 \mathrm{Da}$ $\left({ }^{58} \mathrm{Fe}^{2+}\right.$ peak and $\mathrm{N}_{2}{ }^{+}$peak). The presence of peak overlap at $28 \mathrm{Da}$ can be inferred from the slightly higher intensity of the peak at $29 \mathrm{Da}$ as compared to the expected value for the ${ }^{58} \mathrm{Fe}^{2+}$ isotope (Figure 5(a), dotted encircled area). This suggests that some of the nitrogen atoms are field evaporated as $\mathrm{N}_{2}{ }^{+}$ions. However, most of the ions forming the peaks at 27 , 28 , and $29 \mathrm{Da}$ are probably iron ions. During peak decomposition (as discussed in Section II-B-5), the number of ions in the nonoverlapped peak at $28.5 \mathrm{Da}$ (corresponding solely to the $\mathrm{Fe}$ ions) is used to calculate the expected number of $\mathrm{Fe}$ ions in the overlapped peaks at 28 and 29 Da. Subtracting this number from the respective total number of ions contained in these peaks gives the number of $\mathrm{N}_{2}{ }^{-}$ions. Note that the value thus obtained for the nitrogen concentration cannot be considered as accurate (see Section II-B-5).

Inside the Al-nitrides in regions 1 and 2 (middle row in Figures 5(a) and (b)), there are almost no iron atoms present, as clearly shown by the absence of a peak at $28.5 \mathrm{Da}$ (corresponding to ${ }^{57} \mathrm{Fe}^{2+}$ ). Also the peak heights at 28 and 29 Da correspond very well with the isotope ratio expected for $\mathrm{N}_{2}{ }^{+}$. It is therefore reasonable to assign the entire peak at 28 and $29 \mathrm{Da}$ to $\mathrm{N}_{2}{ }^{+}$ ions. Thus, it is concluded that the Al-nitrides are iron free.
In the mixed nitrides in regions 1 and 2 (bottom row in Figures 5(a) and (b)), the peak at 28.5 Da corresponding to ${ }^{57} \mathrm{Fe}^{2+}$ is present. Here, a similar peak-decomposition procedure as explained for the evaluation of the mass-to-charge spectrum of the entire measurement was applied (see above). Thus, it may be concluded that the mixed nitrides contain iron (but see what follows, especially point (iii) below).

\section{(ii) Lateral diffusion on the tip surface}

It was shown in a recent study ${ }^{[58]}$ that the diffusion of interstitials and of substitutionally dissolved elements on the tip surface can seriously affect the accuracy of the local composition analysis by APT. Such a surface diffusion effect for Fe from the Fe-based matrix is likely not prominent as the field in the APT experiment is adjusted to ensure steady field evaporation of the matrix, i.e., Fe atoms. However, this effect can be more prominent for the case of interstitial atoms such as $\mathrm{N}$. Hence, this possible error has probably only small effect on the value determined for the content of $\mathrm{Fe}$, but it influences seriously the value determined for the content of $\mathrm{N}$ (of the nitrides).

\section{(iii) Local magnification effect (LME)}

The determination of the composition as well as the size and shape of small (size of a few $\mathrm{nm}$ ) precipitates by APT is affected by the so-called local magnification effect (LME) which is caused by ion-trajectory aberrations due to different (zero-barrier) evaporation fields of different kinds of atoms during an APT experiment. The LME has been discussed ${ }^{[59]}$ as a reason for the erroneous detection of Fe inside nitrides. Also, the LME has been discussed as a reason for inaccurate representation of size and shape of tiny precipitates. ${ }^{[31]}$ The influence of LME is limited only if the evaporation fields for ions from the matrix and the precipitate are not too dissimilar. ${ }^{[60]}$ In the case of an $\mathrm{Fe}$ matrix containing nitride precipitates, LME depends on (a) the difference between the field necessary to evaporate a nitride ion 
region $1 ;$ depth $=9 \mu \mathrm{m}$
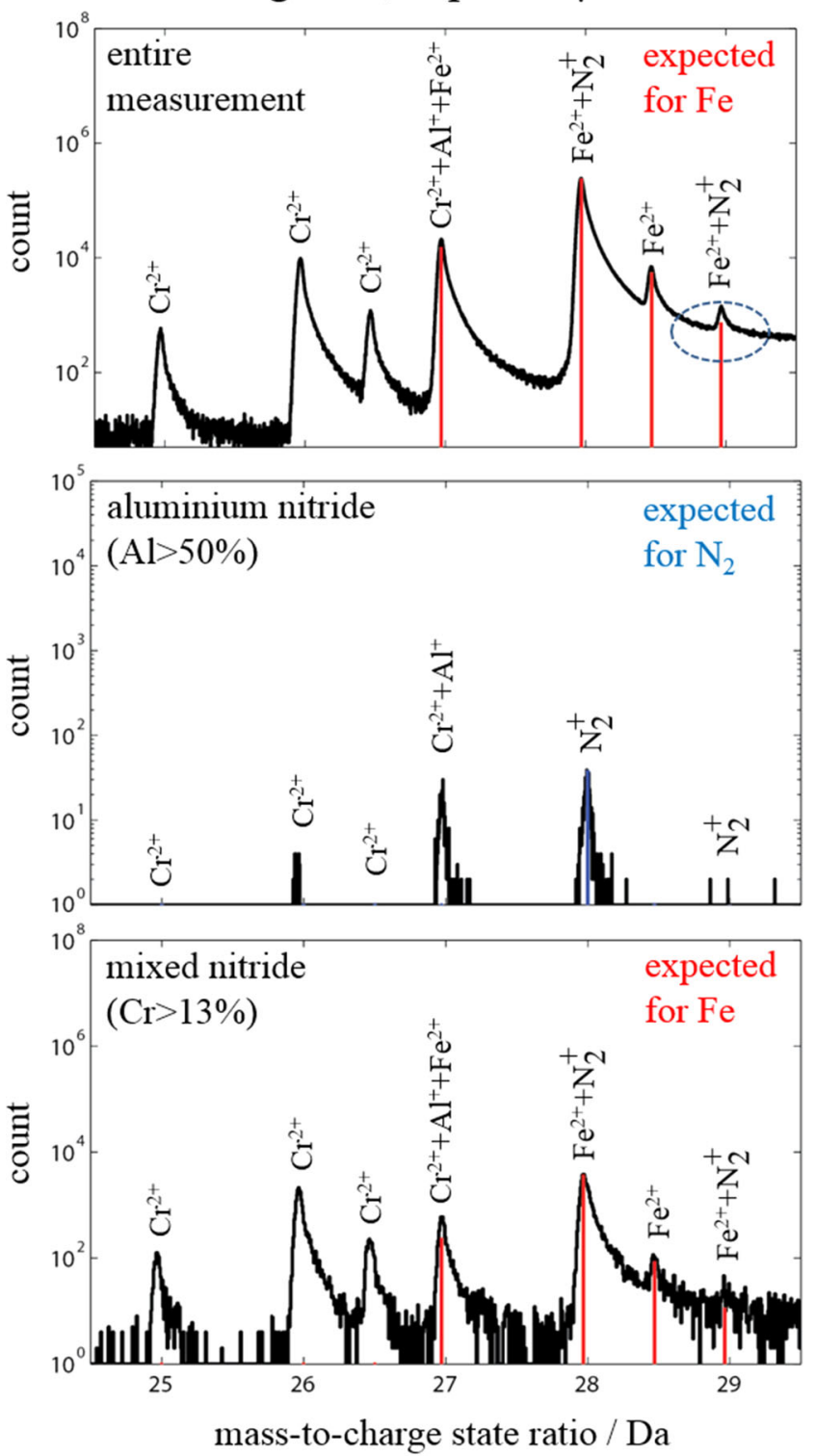

(a) region 2 ; depth $=51 \mu \mathrm{m}$
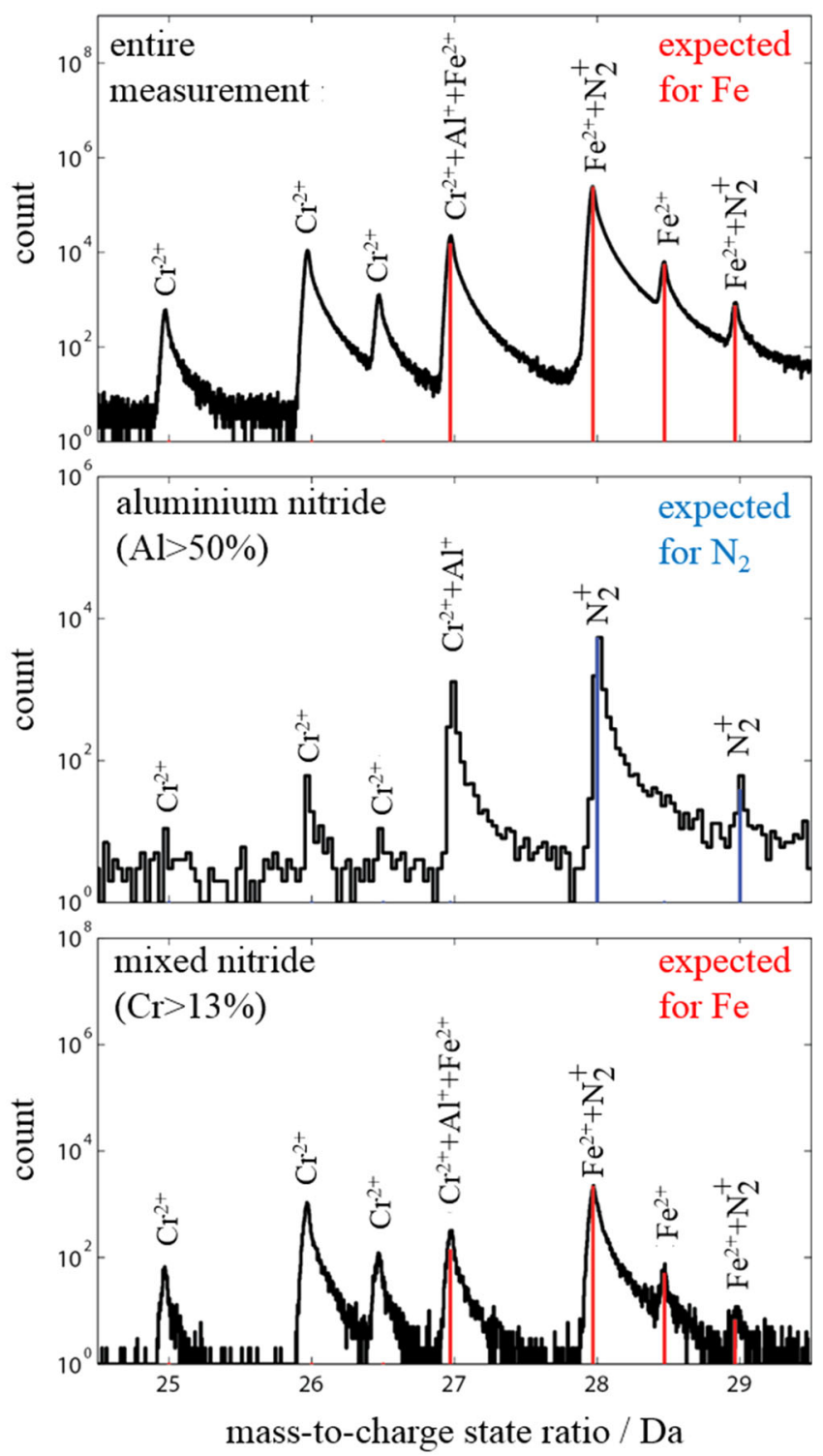

(b)

Fig. 5-Sections of the mass-to-charge spectra recorded during APT experiments for (a) region 1 (depth $=9 \mu \mathrm{m})$ and $(b)$ region 2 $($ depth $=51 \mu \mathrm{m})$ : the mass-to-charge spectrum of the entire measurement (i.e., representative of the overall composition of the specimen) is shown (top row) as well as the spectra for material inside the Al-nitrides (middle row) and the mixed nitrides (bottom row). Additionally, the natural abundances of $\mathrm{Fe}$ (red) and $\mathrm{N}_{2}$ (blue) have been plotted as colored lines.

and the field necessary to evaporate an (iron) ion from the matrix, (b) the size and shape of the precipitate, and (c) even the orientation of this precipitate with respect to the apex of the tip, i.e., the evaporating surface. As a consequence, the presence of a substantial amount of $\mathrm{Fe}$ in the mixed precipitates ( $c f$. Table II) can be an artifact.

There is almost no iron detected in the Al-nitrides (middle row in Figure 5(a)). The LME depends on the chemistry (strength of the bonding) of the precipitates (see point (a) above). Recognizing the metastable nature of the cubic AlN (see also Section IV), it may be suggested that, for the limited strength of the bonding in this nitride, the difference in evaporation field for the ions from the cubic AlN nitride and those from the matrix is relatively small, as compared to the difference in evaporation field for the ions from the mixed nitride and those from the matrix. Thus, the LME could be relatively limited for the AlN nitrides, implying a negligible amount of seemingly present $\mathrm{Fe}$ inside the AlN nitrides (Table II).

From the above discussion, it is concluded that, in any case, the Al-nitrides likely do not contain iron, whereas, in particular owing to the LME effect, the apparent presence of $\mathrm{Fe}$ in the mixed nitrides may be only seemingly so (see further discussion in Section IV). 

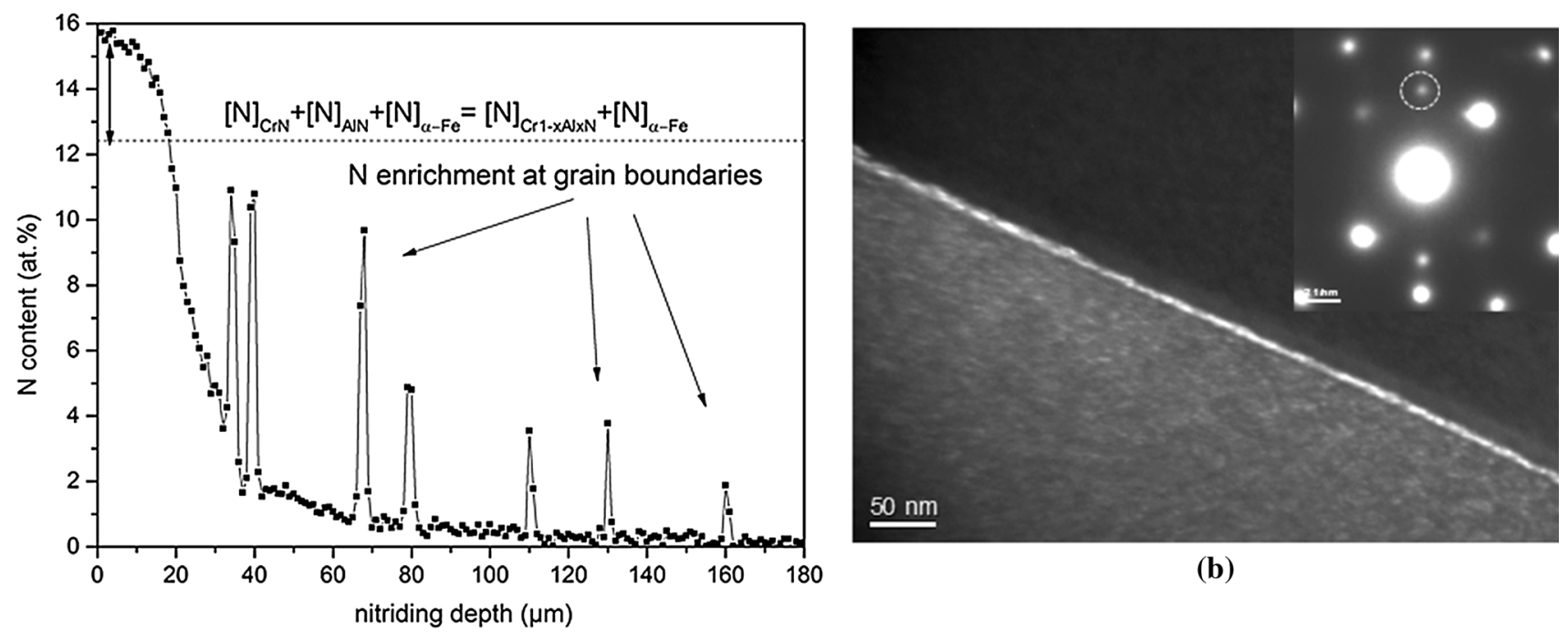

(b)

(a)

Fig. 6 - (a) Nitrogen concentration-depth profile (as determined by EPMA; $c f$. Sect. II-B-2) recorded from the cross section of the recrystallized specimen nitrided for 144 hours. The dashed horizontal line represents the nitrogen level expected for (i) the development of the cubic CrN and AlN or cubic NaCl-type mixed $\mathrm{Cr}_{1-x} \mathrm{Al}_{x} \mathrm{~N}$ nitrides plus (ii) the $\mathrm{N}$ dissolved in the ferrite matrix at the applied nitriding conditions. The nitrogen taken up above the dashed line (indicated by the line piece with two arrowheads in (a)) is called excess nitrogen. (b) DF image and the corresponding SADP recorded from the grain boundary area of a recrystallized specimen nitrided for 144 hours at the depth of $60 \mu \mathrm{m}$. The dark-field image has been obtained using the 002 spot of cubic $\mathrm{NaCl}$-type $M e_{1} \mathrm{~N}, M e_{2} \mathrm{~N}$, or $\left(M e_{1}, M e_{2}\right) \mathrm{N}\left(M e_{1}=\mathrm{Cr}\right.$ and $\left.M e_{2}=\mathrm{Al}\right)$ nitride (shown with white circle in the SADP given in the inset): the grain boundary appears bright indicating the presence of $M e \mathrm{~N}$ nitride at the grain boundary.

By denitriding at a temperature lower than the nitriding temperature, all nitrogen not strongly bonded to $M e$ (as all dissolved/excess $\mathrm{N}$ ) can be removed from the specimen. ${ }^{[61]}$ Such experiments have been performed for a number of the nitrided, ferritic, iron-based binary alloys, ${ }^{[21,62]}$ and also for a nitrided, ferritic, ternary Fe-Cr-Al alloy. ${ }^{[56]}$ In all cases, it was found that the nitrogen remaining in the specimens was compatible with complete precipitation of all $M e$, or $M e_{1}$, and $M e_{2}$, as $M e \mathrm{~N}$ or $\left(M e_{1}, M e_{2}\right) \mathrm{N}$, respectively. This strongly suggests that $\mathrm{Fe}$ is not incorporated in the mixed nitride. It might, however, not be excluded that the Fe possibly initially taken up in the nitrides leaves the nitrides during denitriding if there exists a driving force for this effect. However, the mobility of $\mathrm{Fe}$ (in a nitride) at the relatively low denitriding temperatures can be rather small. The initial incorporation of $\mathrm{Fe}$ in the nitride would then simply be the consequence of Fe not being able "to go out of the way" fast enough. For a related discussion and results from our group on the composition of nitrides developing upon Fe-Cr-Mo alloy, see Reference 31.

\section{Depth Profiles of Nitrogen Content, Stress, and Hardness}

The nitrogen concentration-depth profile, as measured by EPMA on the cross section of the recrystallized specimen nitrided for 144 hours, is shown in Figure 6(a). The surface nitrogen content is above the value expected for (i) the precipitation of all alloying element as stoichiometric nitride (either as separate, binary nitrides AlN and $\mathrm{CrN}$ or as the ternary, mixed nitride $\mathrm{Cr}_{1-x} \mathrm{Al}_{x} \mathrm{~N}$ ) plus (ii) the equilibrium saturation of a stress-free ferrite matrix with dissolved nitrogen. The additional nitrogen uptake above this expected level (indicated by the line piece with two arrowheads in Figure 6(a)) is called "excess nitrogen" (for details about excess nitrogen, see References $21,61,63,64)$. In the deeper region of the nitrided zone of the recrystallized specimen, relatively large $\mathrm{N}$ contents occur at the grain boundaries. This observation, together with the TEM evidence provided in Figure 6(b), indicates the development of cubic rock-salt type nitride precipitates preferably at grain boundaries. This result is compatible with an observation made in Reference 27: Segregation of Al alloying element to ferrite-matrix grain boundaries before nitriding results in heterogeneous nucleation of cubic rocksalt type A1N nitrides at grain boundaries during nitriding.

The nitrogen concentration-depth profile, as measured by EPMA on the cross section of the cold-rolled specimen nitrided for 144 hours, shows two clear plateau regions of more or less constant nitrogen concentration in the nitrided surface-adjacent area (see regions 1 and 2 in Figure 7(a)). This parallels a similar feature observed in the measured hardness-depth profile of the same specimen (see further below) and is compatible with the LM image of Figure 1(d). The near-surface plateau (marked as region 1) corresponds with a nitrogen content in any case compatible with the precipitation of all alloying element as nitride (i.e., either as $\mathrm{CrN}+\mathrm{AlN}$ or as mixed $\mathrm{Cr}_{1-x} \mathrm{Al}_{x} \mathrm{~N}$ ) (see above for uptake of excess nitrogen). 


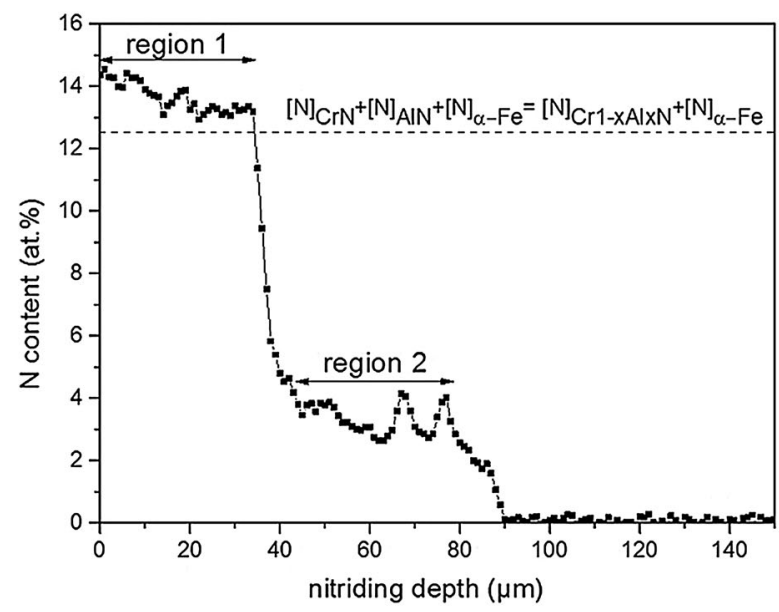

(a)

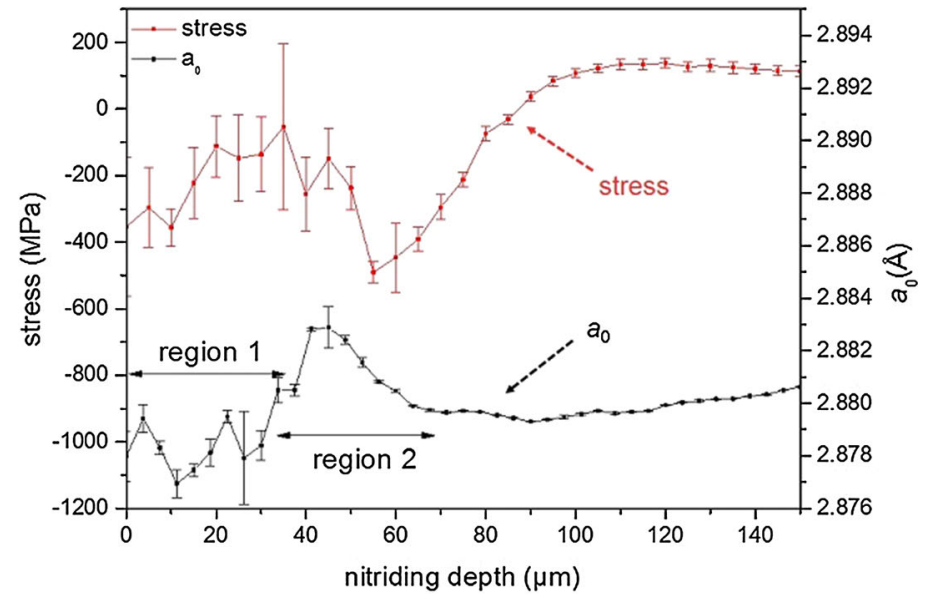

(b)

Fig. 7-(a) Nitrogen concentration-depth profile (as determined by EPMA; $c f$. Sect. II-B-2) recorded from the cross section of the cold-rolled specimen nitrided for $144 \mathrm{~h}$. The dashed horizontal line represents the nitrogen level expected for (i) the development of the cubic NaCl-type $\mathrm{CrN}$ and $\mathrm{AlN}$ or cubic NaCl-type mixed $\mathrm{Cr}_{1-x} \mathrm{Al}_{x} \mathrm{~N}$ nitrides plus (ii) the $\mathrm{N}$ dissolved in the ferrite matrix at the applied nitriding conditions. The nitrogen taken up above the dashed line is called excess nitrogen. (b) The ferrite "strain-free" lattice parameter-depth profile and the residual stress-depth profile as measured on the cross section of the same specimen as in (a).

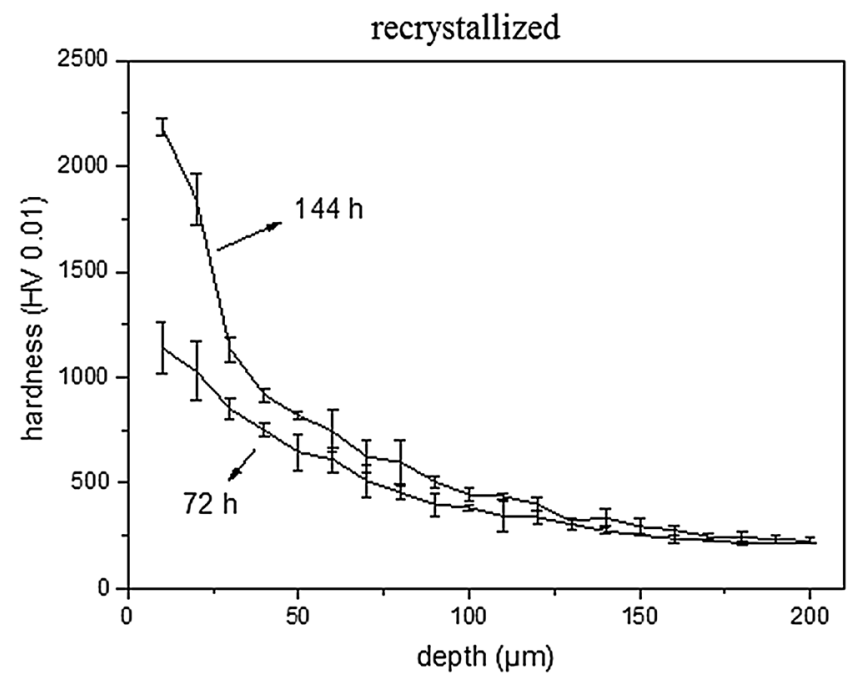

(a)

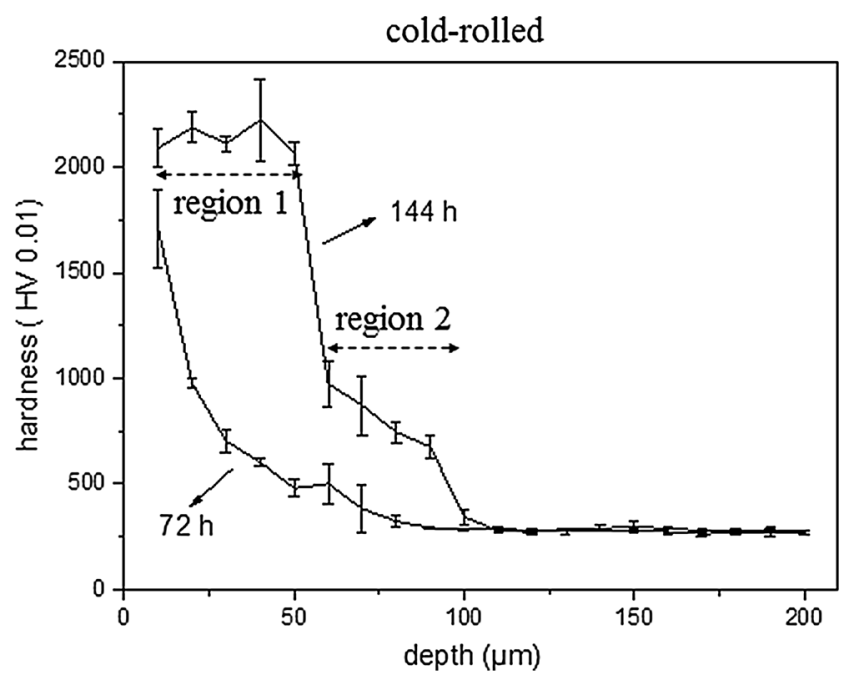

(b)

Fig. 8-Hardness-depth profiles as measured on cross sections of nitrided (a) recrystallized and $(b)$ cold-rolled Fe-Cr-Al specimens.

To investigate in more detail the peculiar, stepped nature of the graded microstructure of the cold-rolled specimen, the "strain-free" lattice parameter of the ferrite matrix and the residual macrostress parallel to the surface of the cold-rolled nitrided specimen, both as a function of depth, have been obtained by applying high-energy synchrotron X-ray diffraction in transmission geometry on a cross section of the cold-rolled Fe-Cr-Al specimen nitrided for 144 hours ( $c f$. Section II-B-3; see Figure 7(b)). Again a distinction of regions 1 and 2 can be made.
The depth profiles of stress and "strain-free" lattice parameter will be discussed starting from the (practically) unnitrided core proceeding from the "newest" nitrided region (region 2) to the "oldest" nitrided region (region 1).**

**The nonnitrided specimen is macrostress free. Of course, a deformed specimen contains microstresses (microstresses induce diffraction-line broadening, (usually) not diffraction-line shift, expressing the presence of macrostress $\left.{ }^{[46,65]}\right)$. 
The development of misfitting (partly coherent) nitride precipitates in region 2 is associated with matrix dilatation $^{[53]}$ that overcompensates the decrease of the lattice parameter due to solute depletion and thus the "strain-free" lattice parameter in region 2 increases in the direction of the surface, starting from the value representing the unnitrided core. The core is practically free of nitrogen and at first sight may be expected to exhibit no or negligible residual stress. The actual occurrence of a residual tensile stress at a depth beyond region 2 can be understood as a consequence of the presence of pronounced compressive stress in the nitrided zone and the requirement of mechanical equilibrium. The volume expansion strived for in region 2 as a consequence of the progressing precipitation process induces the development of compressive residual stress increasing in region 2 in the direction of the surface.

Moving to region 1, the fraction of precipitation increases strongly; in region 1 all alloying element has precipitated (see Figure 7(a)). This would lead to further increase of residual compressive stress. However, the yield limit of the material becomes surpassed at about $-500 \mathrm{MPa}$, and therefore upon progressive nitriding as in region 1, stress relaxation occurs (the stress becomes less compressive); note also the development of macrocracks in the surface-adjacent region of the nitrided recrystallized specimens (Figure 1(b)). Aging of the mixed $(\mathrm{Cr}, \mathrm{Al})$-nitride precipitates can be accompanied with the loss of $\mathrm{Al}$ initially taken up in these nitrides and the subsequent development of separate Al-nitride precipitates, as argued on the basis of the compositional analysis presented in Section III-B. This process can be associated with decreasing coherency for in particular the initial, mixed (Cr, Al)-nitride precipitates. Indeed, the amount of excess nitrogen (an indirect measure for the degree of coherency ${ }^{[19]}$ ) is distinctively less in the fully nitrided, surface-adjacent zone of the cold-rolled specimens, as compared to the recrystallized specimens (cf. Figures 6(a) and 7(a)). The "strain-free" lattice parameter of the matrix in region 1 then decreases with respect to that of region 2 .

Hardness-depth profiles measured on cross sections of the recrystallized and cold-rolled specimens nitrided for different times are shown in Figure 8. After nitriding for 72 hours, a very gradual decrease of hardness as a function of depth is observed for the recrystallized specimen, whereas a less gradual case/core transition is apparent for the corresponding cold-rolled specimen. This observation suggests a more pronounced development of nitride precipitates in the deformed material as compared to the recrystallized material for the same time of nitriding ( $c f$. Figures 8(a) and (b)).

Upon prolonged nitriding (144 hours), further significant increases of hardness occur in the surface region; the hardness rises to $1100 \mathrm{HV}$ and $1700 \mathrm{HV}$ after 72 hours of nitriding for the recrystallized and cold-rolled specimens, respectively, and to about $2100 \mathrm{HV}$ after 144 hours of nitriding for both the cold-rolled and the recrystallized specimens. After prolonged nitriding (144 hours) of the cold-rolled specimens, two nitrided regions occur in the nitrided zone according to the hardness-depth profiles: a zone of high constant hardness adjacent to the surface, followed by a region of much less hardness exhibiting a gradual decrease of hardness with depth (see regions marked as region 1 and region 2 in Figure 8(b)). A similar phenomenon does not occur for the long-time (144 hours) nitrided recrystallized specimen (see Figure 8(a)). These observations are compatible with the etching responses observed in the LM images of the recrystallized and cold-rolled specimens as discussed in Section III-A (cf. Figures 1(b) and (d)) and the above-discussed nitrogen concentration-depth profiles ( $c f$. Figures 6(a) and 7(a)).

\section{NUCLEATION OF NITRIDES: ROLE OF DEFORMATION AND DEPTH DEPENDENCE}

To understand the type of precipitates developing during nitriding of the recrystallized and cold-rolled $\mathrm{Fe}-\mathrm{Cr}-\mathrm{Al}$ alloys, the thermodynamics of precipitation in the recrystallized and cold-rolled specimens has to be considered. In the discussion below, the energy changes upon formation of the various, possible precipitates (cubic $\mathrm{CrN}$, cubic $\mathrm{AlN}$, hexagonal $\mathrm{AlN}$, and mixed $\mathrm{Cr}_{1-x} \mathrm{Al}_{x} \mathrm{~N}$ precipitate with variable $\left.(1-x) / x\right)$ are quantified. It is assumed that all precipitates do not contain iron (see Section III-B).

Considering the nucleation of nitride precipitates in the undeformed (recrystallized) and deformed (coldrolled) ferrite matrices, two types of nucleation can be considered: homogeneous and heterogeneous nucleation (on dislocations). The associated energy changes can be described as follows (for extensive discussion the reader is referred to Reference 9):

(i) Homogeneous precipitation:

The total change in Gibbs energy $(\Delta G)$ upon precipitation of spherical precipitates of radius $r$, from $M e$ and $\mathrm{N}$ atoms dissolved in the matrix, is governed by the change in chemical energy of the system $\left(\Delta G_{\text {chem }}\right.$ per unit volume), the change in elastic strain energy of the assembly $\left(\Delta G_{\text {strain }}\right.$ per unit volume) due to the precipitate/matrix misfit, and the rise of interface energy $(\gamma$, per unit area of interface) due to the emergence of new interface between the precipitate and the matrix. Thus, the total change in Gibbs energy can be given as ${ }^{[8]}$

$$
\Delta G=\frac{4}{3} \pi r^{3}\left(\Delta G_{\text {chem }}+\Delta G_{\text {strain }}\right)+4 \pi r^{2} \gamma
$$

(ii) Heterogeneous nucleation on/along a dislocation line:

In addition to the energy contributions listed above, in the case of heterogeneous nucleation of particles on dislocations, an additional energy change, usually favoring nucleation, has to be taken into account: partial release of dislocation-line energy, initially stored within the precipitate-particle volume, plus the so-called interaction energy of the precipitate/matrix-strain 
field and the dislocation-strain field. Here the cases of coherent and incoherent precipitation have to be distinguished:

(A) Coherent precipitation: for the case of precipitation of a coherent precipitate generally not all of the elastic energy as dislocation-line energy, initially stored in the volume to be occupied by the precipitate, is released (if the elastic constants of both matrix and precipitate are equal and both matrix and precipitate are elastically isotropic, even none of this energy will be liberated). The interaction energy (see above) (then) can promote precipitation on a dislocation. For the case of coherent, cylindrical, elastically isotropic particle of radius $r$ along an edge dislocation in an elastically isotropic matrix, the total change in Gibbs energy per unit length of dislocation thus is given by

$$
\begin{aligned}
\Delta G= & \pi r^{2}\left(\Delta G_{\text {chem }}+\Delta G_{\text {strain }}\right) \\
& +2 \pi r \gamma-B \pi r,
\end{aligned}
$$

where the term $B$ equals $[G b(1+v)|\varepsilon|] /$ $[\pi(1-v)]$, with $G$ and $v$ as the shear modulus and Poisson's ratio, respectively (used for matrix and particle), $b$ the length of the Burgers vector, and $\varepsilon$ the linear misfit parameter.

(B) Incoherent precipitation: for the case of precipitation of an incoherent cylindrical, elastically isotropic particle of radius $r$ along a dislocation in the elastically isotropic matrix, all dislocation-line energy initially stored within the precipitate-particle volume is released and the interaction energy is ignored (fully justified for precipitation on a screw dislocation). Then the total change in Gibbs energy per unit length of dislocation can be written as

$$
\begin{aligned}
\Delta G= & \pi r^{2}\left(\Delta G_{\text {chem }}+\Delta G_{\text {strain }}\right) \\
& +2 \pi r \gamma-A \ln \left(r / r_{\text {core }}\right),
\end{aligned}
$$

where $A$ equals $G b^{2} /[4 \pi(1-v)]$ for edge dislocations and $G b^{2} / 4 \pi$ for screw dislocations and $r_{\text {core }}$ is the radius of the dislocation core, with $G$ and $v$ as the shear modulus and Poisson's ratio of the matrix.

The values of the $\Delta G_{\text {strain }}$ and $\gamma$ depend on the nature of the accommodation of the precipitate/matrix misfit (coherent $v s$ incoherent). The constants used for the calculation of the elastic strain energy contribution are summarized in Table III. The lattice parameters of the mixed $\mathrm{Cr}_{1-x} \mathrm{Al}_{x} \mathrm{~N}$ nitride $((1-x) / x: 1 / 2,1$, and 2$)$ have been obtained as weighted averages of the cubic $\mathrm{CrN}$ and cubic AlN lattice parameters. The bulk moduli of the cubic mixed nitride $\mathrm{Cr}_{1-x} \mathrm{Al}_{x} \mathrm{~N}$ nitride $((1-x) / x$ :

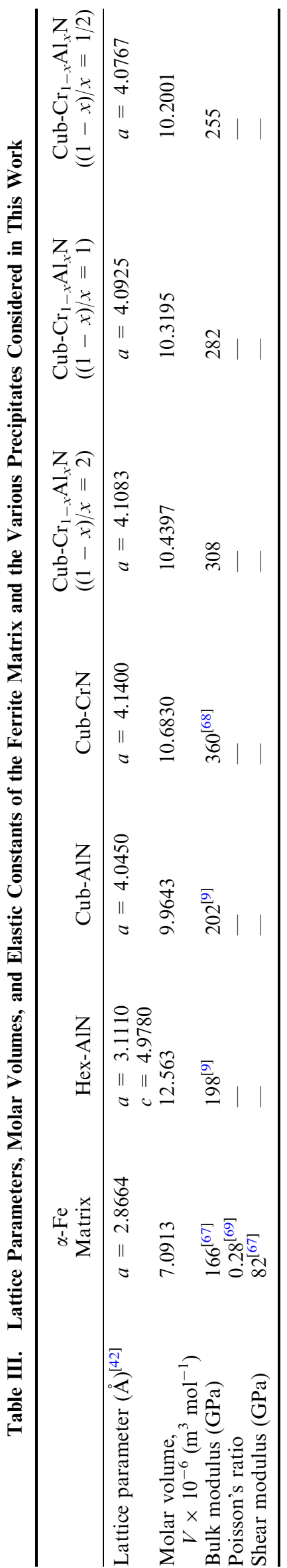

VOLUME 47A, SEPTEMBER 2016-4589 


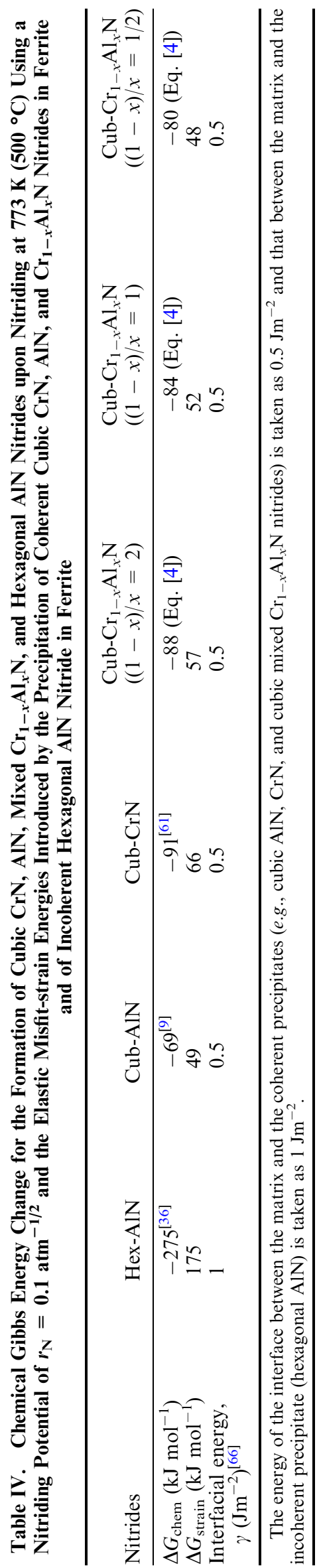

$1 / 2,1$, and 2) have also been obtained as weighted averages of the $\mathrm{CrN}$ and cubic AlN bulk moduli. The values of $\gamma$ have been taken as $0.5 \mathrm{Jm}^{-2}$ for coherent precipitates and as $1 \mathrm{Jm}^{-2}$ for incoherent precipitates. ${ }^{[66]}$ The thus-obtained values of $\Delta G_{\text {strain }}$ for the formation of coherent cubic $\mathrm{CrN}, \mathrm{AlN}$, and $\mathrm{Cr}_{1-x} \mathrm{Al}_{x} \mathrm{~N}((1-x) / x$ : $1 / 2,1$, and 2) nitrides in ferrite and for the formation of the incoherent hexagonal AlN nitride in ferrite are shown in Table IV (for the formulas used for $\Delta G_{\text {strain, }}$ see Appendix B of Reference 9).

The values of $\Delta G_{\text {chem }}$ for the formation of cubic $\mathrm{CrN}$, cubic AlN, and hexagonal AlN nitrides in ferrite are also shown in Table IV. Here, the value of $\Delta G_{\text {chem }}$ is taken as the Gibbs energy for the formation of the precipitate concerned $\left(\Delta G_{\mathrm{f}}\right)$ plus the energy change due to dissolution of nitrogen in $\mathrm{Fe}\left(\Delta G_{\mathrm{N}_{\alpha}}\right)$. The minor energy changes due to dissolution of the alloying elements in Fe ( $c f$. Reference 9) are neglected. The chemical Gibbs energy for the formation of the cubic mixed $\mathrm{Cr}_{1-x} \mathrm{Al}_{x} \mathrm{~N}$ nitride $((1-x) / x: 1 / 2,1$, and 2$)$ has been calculated assuming an ideal mixture of cubic $\mathrm{CrN}$ and cubic AlN nitrides:

$$
\Delta G_{\text {chem }}^{\mathrm{Cr}_{1-x} \mathrm{Al}_{x} \mathrm{~N}}=(1-x) \Delta G_{\mathrm{f}}^{\mathrm{CrN}}+x \Delta G_{\mathrm{f}}^{\mathrm{AlN}}-\Delta G_{\mathrm{N}_{\alpha}}+\Delta G_{\text {mix }}^{\text {ideal }},
$$

where $\Delta G_{\mathrm{f}}^{\mathrm{CrN}}$ and $\Delta G_{\mathrm{f}}^{\mathrm{AlN}}$ are the Gibbs energies for the formation of cubic $\mathrm{CrN}$ and cubic AlN nitrides, respectively, and $\Delta G_{\mathrm{N}_{\alpha}}$ is the Gibbs energy change upon dissolution of $\mathrm{N}$ in ferrite. $\Delta G_{\mathrm{mix}}^{\text {ideal }}$ is the Gibbs energy change upon mixing of $\mathrm{CrN}$ nitride and cubic AlN nitride according to the ideal solid solution model ${ }^{[66]}$ : $\Delta G_{\text {mix }}^{\text {ideal }}=-T \Delta S_{\text {mix }}^{\text {ideal }}, \quad$ where $\quad \Delta S_{\text {mix }}^{\text {ideal }}=-R[(1-x) \ln$ $(1-x)+x \ln x]$ with $R$ as the gas constant and $T$ as the absolute temperature.

The change of the total Gibbs energy of the system as a function of the precipitate radius for precipitation of the binary $\mathrm{CrN}$ and $\mathrm{AlN}$ and for precipitation of the ternary $\mathrm{Cr}_{1-x} \mathrm{Al}_{x} \mathrm{~N}$ in the recrystallized specimens (homogenous nucleation) and in the cold-rolled specimens (heterogeneous nucleation) has been calculated according to Eqs. [1] to [4], and the results are depicted in Figures 9(a) and (b), respectively.

In the present study, a more pronounced development of nitride precipitates in the deformed material as compared to the recrystallized material for the same short duration of nitriding ( 72 hours) has been observed (Figures 8(a) and (b)). The apparently easier development of precipitates in the cold-rolled specimen than in the recrystallized specimen can obviously be ascribed to the absence of an energy barrier for the nucleation of both the mixed nitride and the cubic AlN nitride in the deformed specimens, whereas in the recrystallized specimens such energy barriers do occur ( $c f$. Figures 9(a) and (b)).

Upon nitriding of the recrystallized $\mathrm{Fe}-\mathrm{Cr}-\mathrm{Al}$ specimens, cubic NaCl-type nitride platelets develop (see Figure 3). The absence of the stable hexagonal wurtzitetype modification of AlN in the nitrided recrystallized $\mathrm{Fe}-\mathrm{Cr}-\mathrm{Al}$ alloy is attributed to its larger energy barrier as compared to the nucleation of cubic rock-salt type, mixed ternary $\mathrm{Cr}_{1-x} \mathrm{Al}_{x} \mathrm{~N}$ nitride (compare the dashed 


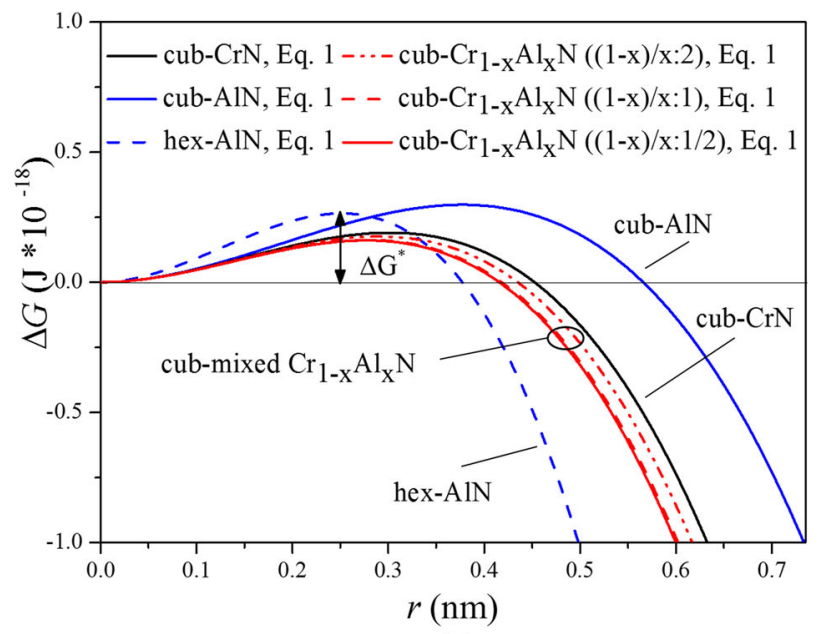

(a)

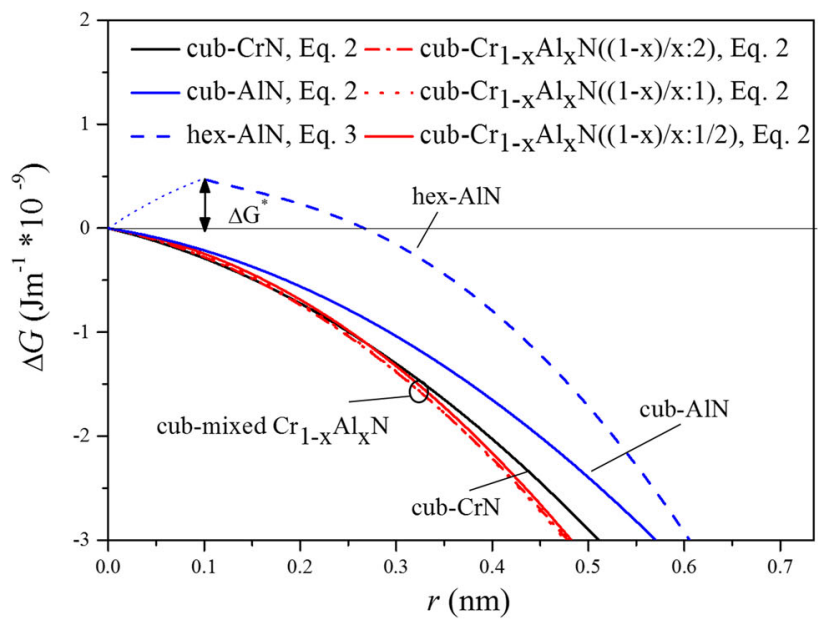

(b)

Fig. 9- Gibbs energy change as a function of nitride particle radius for (a) homogenous precipitation of spherical, coherent, cubic $\mathrm{CrN}$, $\mathrm{AlN}$, and mixed $\mathrm{Cr}_{1-x} \mathrm{Al}_{x} \mathrm{~N}((1-x) / x: 1 / 2,1$, and 2$)$ particles and spherical, incoherent, hexagonal AIN particles in the recrystallized specimen at $773 \mathrm{~K}\left(500{ }^{\circ} \mathrm{C}\right), \Delta \mathrm{G}$ per particle; $(b)$ heterogeneous precipitation of cylindrical, coherent, cubic $\mathrm{CrN}, \mathrm{AlN}$, and mixed $\mathrm{Cr}_{1-x} \mathrm{Al}_{x} \mathrm{~N}((1-x) / x: 1 / 2,1$, and 2$)$ and cylindrical incoherent, hexagonal AlN particles on dislocations in the cold-rolled specimen at $773 \mathrm{~K}\left(500{ }^{\circ} \mathrm{C}\right), \Delta G$ per particle and per unit length of dislocation. $\Delta G^{*}$ is the activation energy barrier for thermally activated nucleation.

blue and red curves in Figures 9(a)). The incorporation of $\mathrm{Al}$ into $\mathrm{CrN}$ decreases the misfit-strain energy more than the formation of mixed nitride which increases the chemical Gibbs energy ${ }^{[38]}$ (see Table IV).

In the case of the recrystallized specimen, the formation of only one type of cubic rock-salt nitride occurs: mixed ternary $\mathrm{Cr}_{1-x} \mathrm{Al}_{x} \mathrm{~N}$ nitride (see Figures 3(a) and (b); see also electron energy loss spectroscopy (EELS) analyses in Reference 55). This can be ascribed to the larger energy barrier and larger critical size for nucleation of cubic AlN and $\mathrm{CrN}$ nitrides as compared to energy barrier and critical size for nucleation of the mixed ternary $\mathrm{Cr}_{1-x} \mathrm{Al}_{x} \mathrm{~N}$ nitride (compare the blue, black, and red curves in Figure 9(a)).
Upon nitriding of the cold-rolled $\mathrm{Fe}-\mathrm{Cr}-\mathrm{Al}$ specimens, cubic mixed $\mathrm{Cr}_{1-x} \mathrm{Al}_{x} \mathrm{~N}$ and cubic binary AlN nitride develop (see Figure 4). No energy barrier $\left(\Delta G^{*}\right)$ for nucleation of both types of precipitates exists (see the solid blue and red curves in Figure 9(b)), whereas this does not hold for the precipitation of hexagonal AIN. The emergence of cubic AlN, next to cubic mixed $\mathrm{Cr}_{1-x} \mathrm{Al}_{x} \mathrm{~N}$, in the cold-rolled specimens, in contrast with the recrystallized specimens, can be a consequence of the absence of an energy barrier for the nucleation of both types of nitride in the cold-rolled specimens and the relatively minor differences in released Gibbs energy upon their precipitation.

The development of a stepped nature for the nitrogen concentration-depth profile upon prolonged nitriding of the cold-rolled specimens (see Figure 7(a)) may now be discussed as follows. Upon prolonged nitriding, the deepest part of the nitrided zone occurs at a continuously larger depth. Consequently, with reference to the concentration gradient of dissolved nitrogen in the nitrided zone, the (nitrogen) supersaturation becomes continuously smaller for the deepest part of the nitrided zone. In the case of the cold-rolled specimens, there is no nucleation barrier for nitride precipitates and hence the development of nitrides takes place more or less instantaneously upon arrival of nitrogen even at these large depths where only a slight (nitrogen) supersaturation prevails (such immediate precipitation of nitrides at such low (nitrogen) supersaturation is not possible for the recrystallized specimens where nucleation barriers occur for nitride precipitation). To realize full precipitation at these large depths, further transport of nitrogen from the surface is needed, which takes time. Hence for the cold-rolled specimens, upon prolonged nitriding, as a consequence of instantaneous nucleation, upon arrival of nitrogen, and nitrogen-transport rate-limited precipitate growth, a zone of incompletely precipitated alloying element nitrides can develop (region 2) underneath the surface-adjacent zone (region 1) where full precipitation has been realized in relatively short time due to a relatively short diffusion path for nitrogen. The absence of such stepped nature for the nitrogen concentration-depth profile of the recrystallized specimens thus reflects a significantly smaller difference of the rates of nucleation and growth of the nitrides.

As follows from numerical analysis on the basis of Eq. [4], rejection of $\mathrm{Al}$ from the mixed nitride, $\mathrm{Cr}_{1-x} \mathrm{Al}_{x} \mathrm{~N}$, and its precipitation as cubic $\mathrm{AlN}$ lead to a (slight) decrease of chemical energy for the system. Aging of the microstructure in the (oldest part of the nitrided zone) has relaxed (partially) the misfit-strain energy initially induced by the precipitation of the mixed nitride ( $c f$. Table IV), thereby making the mixed nitride relatively less favorable. Then this release of chemical Gibbs energy, by the development of AlN from the mixed nitride, may provide the driving force for $\mathrm{Al}$ leaving the mixed nitride upon aging $(=$ prolonged nitriding) and thus explains that the atomic $\mathrm{Al} / \mathrm{Cr}$ ratio in the "newest" region 2 is closer to the atomic $\mathrm{Al} / \mathrm{Cr}$ ratio of the alloy (1.3 vs 2) than that of the "oldest" region 1 ( $0.8 v s$ 2) (see data in Section III-B). 


\section{CONCLUSIONS}

1. The microstructure, recrystallized $v s$ deformed (here cold-rolled), strongly influences the nitride precipitation behavior observed upon nitriding a ternary $\mathrm{Fe}-\mathrm{Cr}-\mathrm{Al}$ alloy.

2. The less gradual case/core transition of the nitrided, cold-rolled specimen, as compared to the corresponding, nitrided, recrystallized specimen, is due to a more rapid development of nitride precipitates in the deformed material. The depth to which some of the inwardly diffusing nitrogen has arrived is, consequently, larger for the recrystallized specimen.

3. Nitride development in the deformed microstructure occurs without nucleation barriers for cubic mixed $\mathrm{Cr}_{1-x} \mathrm{Al}_{x} \mathrm{~N}$ and cubic $\mathrm{AlN}$, which nitrides are observed. Precipitation of hexagonal AlN is associated with a nucleation barrier and is not observed.

4. Nitride development in the recrystallized microstructure occurs with a nucleation barrier which is the smallest for cubic mixed $\mathrm{Cr}_{1-x} \mathrm{Al}_{x} \mathrm{~N}$, which is the only nitride observed.

5. Upon prolonged nitriding ( = aging for the already nitrided zone), $\mathrm{Al}$ becomes rejected from the mixed $\mathrm{Cr}_{1-x} \mathrm{Al}_{x} \mathrm{~N}$ in the deformed specimens and precipitates as cubic AlN, as this leads to a decrease of chemical Gibbs energy of the system. This corresponds to a $\mathrm{Al} / \mathrm{Cr}$ ratio of the mixed $\mathrm{Cr}_{1-x} \mathrm{Al}_{x} \mathrm{~N}$ decreasing with the decreasing depth.

6. Upon prolonged nitriding, a stepped nature of the nitrogen concentration-depth profile emerges for the deformed specimens. This is a consequence of the instantaneous precipitation of nitride upon arrival of nitrogen at already very low supersaturation (as no nucleation barrier must be overcome) and a nitrogen transport rate becoming ever more limiting for nitride precipitate growth with increasing depth.

\section{ACKNOWLEDGMENTS}

Open access funding provided by Max Planck Society. The authors thank Mrs. S. Haug for assistance with the EPMA experiments, Mr. P. Kress for assistance with the nitriding experiments, Mr. W. D. Lang for preparation of TEM specimens, and Dr. B. Rheingans for scientific discussion (all with Max Planck Institute for Intelligent Systems). Further, the authors are grateful to Professor Dr. J. Keckes (Department of Materials Physics, Montanuniversität Leoben, Austria) for the joint development of the cross-sectional transmission X-ray microdiffraction method and Dr. N. Schell (Institute of Materials Research, Helmholtz-Zentrum Geesthacht, Germany) for the technical assistance during beamtime at the HEMS beamline P07 at PETRA III.

\section{OPEN ACCESS}

This article is distributed under the terms of the Creative Commons Attribution 4.0 International License (http://creativecommons.org/licenses/by/4.0/), which permits unrestricted use, distribution, and reproduction in any medium, provided you give appropriate credit to the original author(s) and the source, provide a link to the Creative Commons license, and indicate if changes were made.

\section{REFERENCES}

1. E.J. Mittemeijer and M.A.J. Somers: Thermochemical Surface Engineering of Steels, Woodhead Publishing, Amsterdam, 2015.

2. H.J. Grabke: Berichte Der Bunsen-Gesellschaft Fur Physikalische Chemie, 1968, vol. 72, pp. 533-41.

3. H.J. Grabke: Berichte Der Bunsen-Gesellschaft Fur Physikalische Chemie, 1968, vol. 72, pp. 541-48.

4. E.J. Mittemeijer and J.T. Slycke: Surf. Eng., 1996, vol. 12, pp. $152-62$.

5. E.J. Mittemeijer: in ASM Handbook, Steel Heat Treating Fundamentals and Processes, J. Dossett and G.E. Totten, eds., ASM, Materials Park, 2013, pp. 619-46.

6. K.M. Winter and J. Kalucki: in ASM Handbook, Steel Heat Treating Fundamentals and Processes, J. Dossett and G. E. Totten, ASM, Materials Park, 2013, pp. 647-75.

7. D.H. Jack and K.H. Jack: Mater. Sci. Eng., 1973, vol. 11, pp. 1-27.

8. E.J. Mittemeijer: Fundamentals of Materials Science, Springer, Berlin, 2010.

9. M.H. Biglari, C.M. Brakman, E.J. Mittemeijer, and S. Vanderzwaag: Metall. Mater. Trans. A, 1995, vol. 26A, pp. 765-76.

10. M.H. Biglari, C.M. Brakman, and E.J. Mittemeijer: Philos. Mag. A Phys. Condens. Matter Struct. Defects Mech. Prop., 1995, vol. 72, pp. 1281-99.

11. H. Selg, E. Bischoff, S.R. Meka, R.E. Schacherl, T. Waldenmaier, and E.J. Mittemeijer: Metall. Mater. Trans. A, 2013, vol. 44A, pp. 4059-70.

12. B. Mortimer, P. Grieveson, and K.H. Jack: Scand. J. Metall., 1972, vol. 1, pp. 203-09.

13. E.J. Mittemeijer, A.B.P. Vogels, and P.J. Schaaf: J. Mater. Sci., 1980, vol. 15, pp. 3129-40.

14. R.E. Schacherl, P.C.J. Graat, and E.J. Mittemeijer: Zeitschrift Fur Metallkunde, 2002, vol. 93, pp. 468-77.

15. M. Sennour, P.H. Jouneau, and C. Esnouf: J. Mater. Sci., 2004, vol. 39, pp. 4521-31.

16. G. Miyamoto, A. Yonemoto, Y. Tanaka, T. Furuhara, and T. Maki: Acta Mater., 2006, vol. 54, pp. 4771-79.

17. H.H. Podgurski and H.E. Knechtel: Trans. Metall. Soc. AIME, 1969, vol. 245, pp. 1595-1602.

18. WD Welch and SH Carpente: Acta Metall., 1973, vol. 21, pp. 1169-79.

19. S.S. Hosmani, R.E. Schacherl, and E.J. Mittemeijer: Acta Mater., 2005, vol. 53, pp. 2069-79.

20. D.H. Jack: Acta Metall., 1976, vol. 24, pp. 137-46.

21. H.H. Podgurski and F.N. Davis: Acta Metall., 1981, vol. 29, pp. $1-9$.

22. G.P. Huffman and H.H. Podgurski: Acta Metall., 1975, vol. 23, pp. 1367-79.

23. S.R. Meka, K.S. Jung, E. Bischoff, and E.J. Mittemeijer: Philos. Mag., 2012, vol. 92, pp. 1435-55.

24. S.R. Meka, E. Bischoff, B. Rheingans, and E.J. Mittemeijer: Philos. Mag. Lett., 2013, vol. 93, pp. 238-45. 
25. H.P. van Landeghem, M. Gouné, S. Bordère, F. Danoix, and A. Redjaïmia: Acta Mater., 2015, vol. 93, pp. 218-34.

26. A.R. Clauss, E. Bischoff, R.E. Schacherl, and E.J. Mittemeijer: Philos. Mag., 2009, vol. 89, pp. 565-82.

27. A.R. Clauss, E. Bischoff, R.E. Schacherl, and E.J. Mittemeijer: Mater. Sci. Technol., 2010, vol. 26, pp. 297-308.

28. K.S. Jung, S.R. Meka, R.E. Schacherl, E. Bischoff, and E.J. Mittemeijer: Metall. Mater. Trans. A Phys. Metall. Mater. Sci., 2012, vol. 43, pp. 934- 44.

29. K.S. Jung, R.E. Schacherl, E. Bischoff, and E.J. Mittemeijer: Metall. Mater. Trans. A Phys. Metall. Mater. Sci., 2012, vol. 43, pp. 763-73.

30. A.M. Maliska, J.A. de Cezaro, J.G. Justino and A.N. Klein: in The Proceeding of Advances in Powder Metallurgy and Particulate Materials, Chicago, 1997, pp. 13-169.

31. T. Steiner, S.R. Meka, B. Rheingans, E. Bischoff, T. Waldenmaier, G. Yeli, T.L. Martin, P.A.J. Bagot, M.P. Moody, and E.J. Mittemeijer: Philos. Mag., 2016, vol. 96, pp. 1509-37.

32. M. Udyavar and D.J. Young: Corros. Sci., 2000, vol. 42, pp. 861-83.

33. H. Atmani and O. Thoumire: Bull. Mater. Sci., 2002, vol. 25, pp. 219-25.

34. T. Steiner, S.R. Meka, E. Bischoff, T. Waldenmaier, and E.J. Mittemeijer: Surf. Coat. Technol., 2016, vol. 291, pp. 21-33.

35. W. Roberts, P. Grieveson, and K.H. Jack: J. Iron Steel Inst. (Lond.), 1972, vol. 210, pp. 931-37.

36. B. Schwarz, S.R. Meka, R.E. Schacherl, E. Bischoff, and E.J. Mittemeijer: Acta Mater., 2014, vol. 76, pp. 394-403.

37. B Schwarz, PJ Rossi, L Straßberger, F Jörg, SR Meka, E Bischoff, RE Schacherl, and EJ Mittemeijer: Philos. Mag., 2014, vol. 94, pp. 3098-3119.

38. A.R. Clauss, E. Bischoff, S.S. Hosmani, R.E. Schacherl, and E.J. Mittemeijer: Metall. Mater. Trans. A, 2009, vol. 40A, pp. 1923-34

39. E. Lehrer: Z. Elektrochem., 1930, vol. 36, pp. 383-92.

40. E.J. Mittemeijer and M.A.J. Somers: Surf. Eng., 1997, vol. 13, pp. $483-97$.

41. J.L. Pouchou and F. Pichoir: Recherche Aerospatiale, 1984, vol. 5, pp. 349-67.

42. ICDD Data Base, PCPDFWIN, 2002.

43. N. Schell, A. King, F. Beckmann, T. Fischer, M. Müller, and A Schreyer: Mater. Sci. Forum, 2013, vol. 772, pp. 57-61.

44. S.J.B. Kurz, S.R. Meka, N. Schell, W. Ecker, J. Keckes, and E.J. Mittemeijer: Acta Mater., 2015, vol. 87, pp. 100-10.

45. N.E. Vives Diaz, R.E. Schacherl, L.F. Zagonel, and E.J. Mittemeijer: Acta Mater., 2008, vol. 56, pp. 1196-208.

46. U. Welzel, J. Ligot, P. Lamparter, A.C. Vermeulen, and E.J. Mittemeijer: J. Appl. Crystallogr., 2005, vol. 38, pp. 1-29.

47. W.B. Pearson: A Handbook of Lattice Spacings and Structures of Metals and Alloys, Pergamon, New York, 1958, p. 634.
48. K. Thompson, D. Lawrence, D.J. Larson, J.D. Olson, T.F. Kelly, and B. Gorman: Ultramicroscopy, 2007, vol. 107, pp. 131-39.

49. J.R. De Laeter, J.K. Bohlke, P. De Bievre, H. Hidaka, H.S. Peiser, K.J.R. Rosman, and P.D.P. Taylor: Pure Appl. Chem., 2003, vol. 75 , pp. 683-800.

50. M. Fonović, A. Leineweber, O. Robach, E.A. Jägle, and E.J. Mittemeijer: Metall. Mater. Trans. A Phys. Metall. Mater. Sci., 2015, vol. 46, pp. 4115-31.

51. T. Steiner, M. Akhlaghi, S.R. Meka, and E.J. Mittemeijer: $J$. Mater. Sci., 2015, vol. 50, pp. 7075-86.

52. E.J. Mittemeijer, P. van Mourik, and T.H. de Keijser: Philos. Mag. A Phys. Condens. Matter Struct. Defects Mech. Prop., 1981, vol. 43, pp. 1157-64.

53. M. Akhlaghi, T. Steiner, S.R. Meka, A. Leineweber, and E.J. Mittemeijer: Acta Mater., 2015, vol. 98, pp. 254-62.

54. R.G. Baker and J. Nutting: Iron Steel Inst. Spec. Rep., 1959, vol. 64 , pp. 1-22.

55. K.S. Jung, R.E. Schacherl, E. Bischoff, and E.J. Mittemeijer: Phil. Mag., 2011, vol. 91, pp. 2382-2403.

56. A.R. Clauss, E. Bischoff, S.S. Hosmani, R.E. Schacherl, and E.J. Mittemeijer: Metall. Mater. Trans. A Phys. Metall. Mater. Sci., 2009, vol. 40A, pp. 1923-34.

57. M. Jung, S.R. Meka, B. Rheingans, and E.J. Mittemeijer: Metall. Mater. Trans. A, 2016, vol. 47A, pp. 1425-39.

58. B. Gault, F. Danoix, K. Hoummada, D. Mangelinck, and H. Leitner: Ultramicroscopy, 2012, vol. 113, pp. 182-91.

59. D.Q. Wang, F. Ernst, H. Kahn, and A.H. Heuer: Metall. Mater. Trans. A Phys. Metall. Mater. Sci.Science, 2014, vol. 45A, pp. 3578-85.

60. E.A. Jägle, P.P. Choi, and D. Raabe: Microsc. Microanal., 2014, vol. 20, pp. 1662-71.

61. M.A.J. Somers, R.M. Lankreijer, and E.J. Mittemeijer: Philos. Mag. A, 1989, vol. 59, pp. 353-78.

62. S.S. Hosmani, R.E. Schacherl, and E.J. Mittemeijer: J. Mater. Sci., 2008, vol. 43, pp. 2618-24.

63. P. Jessner, M. Goune, R. Danoix, B. Hannoyer, and F. Danoix: Philos. Mag. Lett., 2010, vol. 90, pp. 793-800.

64. G. Miyamoto, Y. Tomio, H. Aota, K. Oh-ishi, K. Hono, and T. Furuhara: Mater. Sci. Technol., 2011, vol. 27, pp. 742-46.

65. E.J. Mittemeijer and U. Welzel: Modern Diffraction Methods, Wiley, Weinheim, 2013.

66. D.A. Porter and K.E. Easterling: Phase Transformations in Metals and Alloys, Van Nostrand Reinhold, London, 1982.

67. H. Wawra: Zeitschrift für Metallkunde, 1978, vol. 69, pp. 518-23.

68. J. Grossman, A. Mizel, M. Côté, M. Cohen, and S. Louie: Phys. Rev. B, 1999, vol. 60, pp. 6343-47.

69. C.J. Smithells: Metals Reference Book, 5, Butterworth \& Co., London, 1976. 